
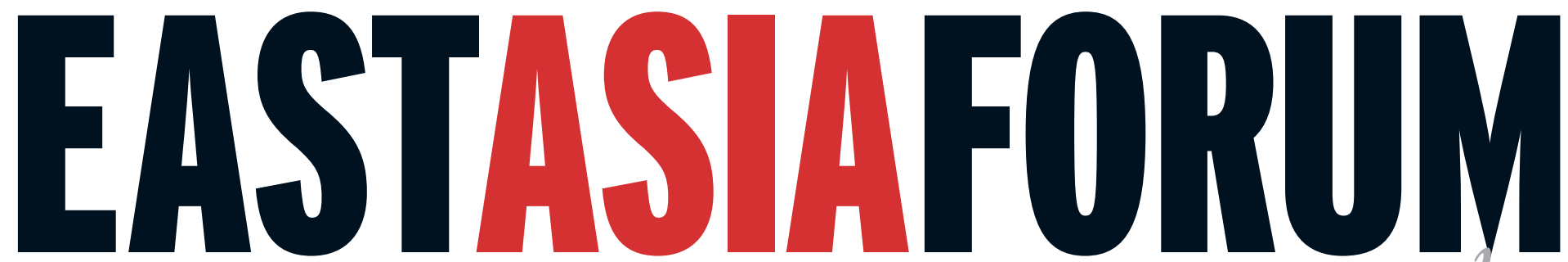

ECONOMICS, POLITICS AND PUBLIC POLICY IN EAST ASIA AND THE PACIFIC

Vol.7 No.4 October-December $2015 \$ 9.50$
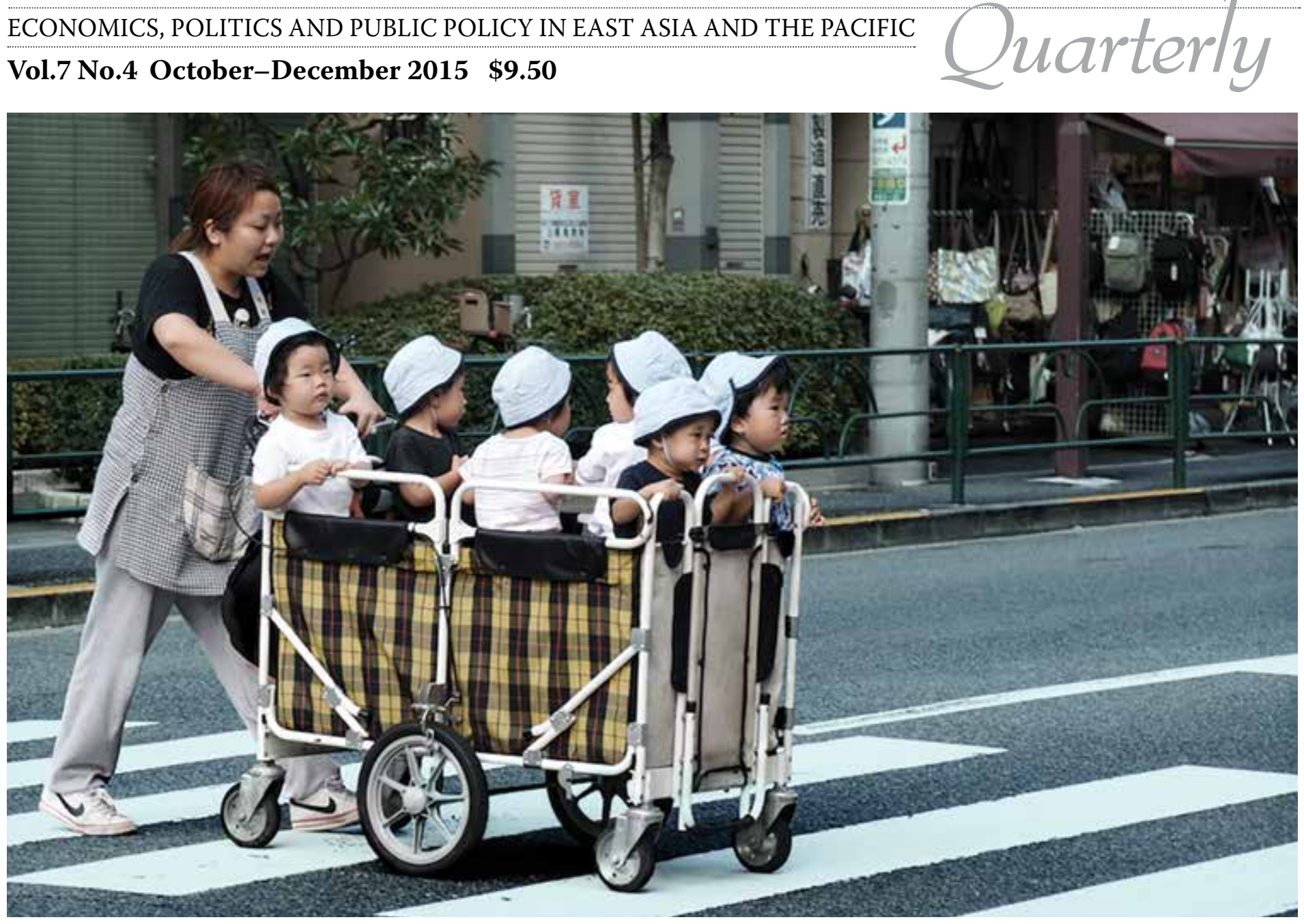

\title{
Asia's Intergenerational Challenges
}

Alan J. Auerbach: The fiscal challenges of the future

ZhongXiang Zhang: China going green

Peter McDonald: Asia's Silver Tsunami

Cai Fang and Lu Yang: New age of Chinese growth

ASIAN REVIEW: Nicholas Farrelly - Long live the King in Thailand ASIAN REVIEW: Laura Dales - Moving beyond marriage in Japan 


\section{EASTASIAFORUM \\ . \\ ISSN 1837-5081 (print) \\ ISSN 1837-509X (online)}

\section{From the Editors' Desk}

The coming decades will present significant intergenerational policy challenges, as well as opportunities, for economies throughout the Asia Pacific region. Economic prosperity and its sustainability will be influenced by how we respond to a number of core drivers, including the re-emergence of Asia as a major centre of the global economy, rapid demographic change, environmental pressures and technological advances.

These drivers will put additional pressure on the fiscal sustainability and on the institutions that have contributed greatly to economic performance to date. These things are often taken for granted but will have significant implications for future economic prosperity throughout the region.

Already a growth engine of the global economy, Asia will be home to the largest middle class population in the world before too long. The associated opportunities and the risks make it necessary that we have the right global, regional and country policy frameworks.

The Asian century will also see rapid demographic change. The ageing of populations throughout the region and changing community expectations about the provision of public services, will see increased demand for health and aged care. The fiscal policy responses to these pressures are yet to be figured out.

Another changing feature of this century will be climate change. To avoid catastrophic climate change substantial and sustained reductions of greenhouse gas emissions are needed. Unfortunately some climate change will now be unavoidable and economies will also need to adapt to higher temperatures.

How countries, such as China, transition to high-income status will also be crucial. Policy frameworks that help facilitate industrial upgrading, innovation and investment in human capital will be important to drive productivity and avoid the so-called middle income trap.

These are the questions with which this issue of East Asia Forum Quarterly deals.

One common theme highlighted in the articles is that the economies throughout the region need to begin preparing for the challenges and opportunities of the future. The policy actions taken or missed today will have a significant bearing on future outcomes.

\section{Shane Johnson and Shiro Armstrong}

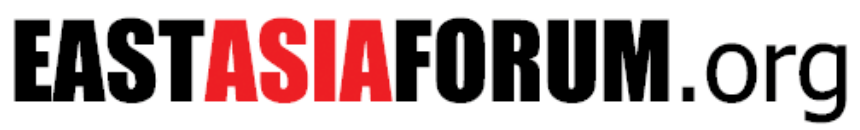

\section{CONTENTS}

\section{KEN HENRY}

Knocking at the door of opportunity 6 ALAN J. AUERBACH

Facing up to the long-term fiscal challenges

\section{PETER MCDONALD}

Growing old before growing rich

11 CAI FANG AND LU YANG

New age of Chinese growth

13 ATSUSHI SEIKE

Japan's race against the ageing clock

15 LAURA DALES

ASIAN REVIEW: Moving beyond marriage in Japan

19 NICHOLAS FARRELLY

ASIAN REVIEW: What happens when the king's gone?

\section{FRANK JOTZO}

ASIAN REVIEW: China takes the lead in new climate change paradigm

\section{YONGSHENG ZHANG}

ASIAN REVIEW: Eco-solutions for a sustainable Asia

32 ZHONGXIANG ZHANG

How to go green without its being a struggle

34 KEVIN J. MUMFORD

Wealth accounting is critical for measuring sustainability

\section{R. QUENTIN GRAFTON, JOHN WILLIAMS AND QIANG JIANG}

A critical balancing act

39 LAWRENCE J. LAU AND JUNGSOO PARK

Productivity lessons for Asia's tiger cubs 41 JENNY GORGON

Keeping productive after the boom

COVER: Toddlers from a Japanese child care centre are pushed along in their nursery cart in Tokyo on 30 July 2009

Photo by Pieterjan Vandaele, https://www.flickr.com/ photos/pjanvandaele/, used with permission. 


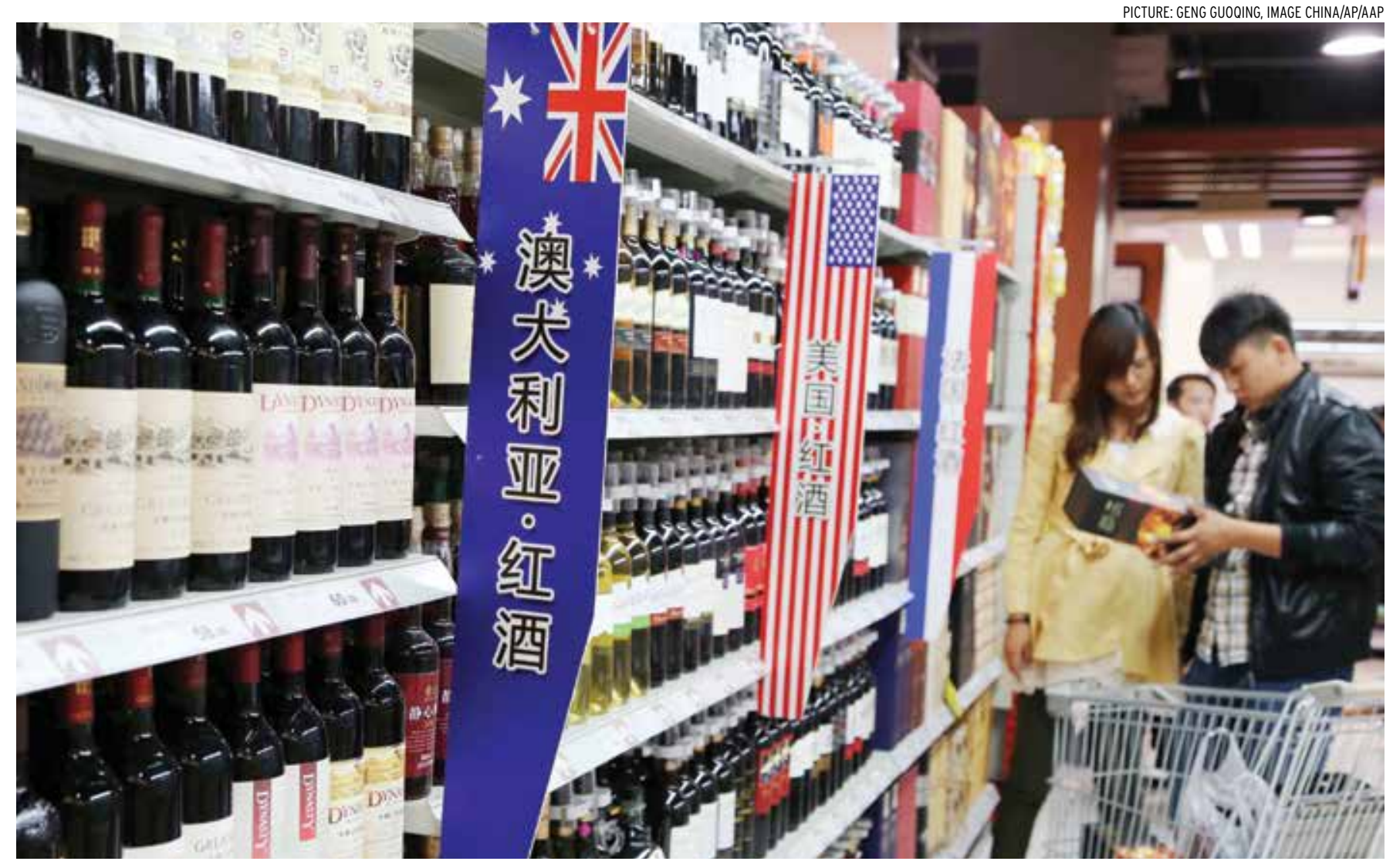

Chinese customers shop for bottled wine imported from Australia at a supermarket in Xuchang City, central China. If 'international competitiveness' is to remain a useful phrase in the Asian century it will have to leave mercantilism behind and be framed in terms of national endowments and capabilities.

\section{Knocking at the door of opportunity}

\section{KEN HENRY}

N 2012, Australia's Asian Century

White Paper outlined fundamental policy and attitudinal changes that would be required if Australia was to make the most of the opportunities presented by the Asian century. Yet it has had no impact on policy in Australia. That could be because it presented a fundamental challenge to the populist narrative of 'Australian mercantilism' that had been used to explain all economic reforms in Australia since the early 1980s.
It is now time to move on from this populist narrative and embrace the core propositions of the Asian century paper.

The narrative of Australian mercantilism and its focus on 'international competitiveness' and the real exchange rate proved powerful in motivating a broad set of reforms in the 1980s and 1990s. But at the same time, the world was changing for Australia in a way that would ultimately render the narrative misguided and dangerous.

In 1978 the Chinese government embarked on an ambitious growth program based on economic liberalisation and internationalisation. In just the past 20 years, China and India have almost trebled their share of the global economy and increased their absolute economic size six times over. More than 40 per cent of global economic activity now occurs in Asia. Today there are about 500 million people in Asia's 'middle class'. By 2030, that's expected to rise to more than 3 billion.

In the late 20th century, China's internationalisation rarely rated a 


\section{EASTASIAFORUM} EDITORIAL STAFF

\section{Issue Editors}

Shane Johnson is a doctoral candidate in economics at the Australian National University and is currently on leave from the Australian Treasury.

Shiro Armstrong, Crawford School of Public Policy, ANU.

\section{Series Editors}

Peter Drysdale, Head, East Asia Forum and East Asian Bureau of Economic Research at the Crawford School of Public Policy, ANU.

Shiro Armstrong, Director, AustraliaJapan Research Centre and Executive Director, EAF and EABER, Crawford School, ANU.

\section{Editorial Staff}

Coordination: Mark Fabian.

Editing: Alison Darby, Owen Hutchinson, Patrick Deegan, Linda Ma, Amanda Maclean, Nawaaz Khalfan, Stephen Norman, Catherine Yen, ANU.

Editorial Advisers: Peter Fuller, Max Suich.

Production: Dario Postai.

Original design: Peter Schofield.

Email Peter.Drysdale@anu.edu.au, Shiro.Armstrong@anu.edu.au.

The views expressed are those of the individual authors and do not represent the views of the Crawford School, ANU, $E A B E R, E A F$, or the institutions to which the authors are attached.

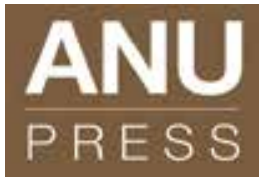

Published by ANU Press The Australian National University Canberra ACT 0200, Australia Email: anupress@anu.edu.au Web: http://press.anu.edu.au mention in Australian policy circles. Australia failed to anticipate the acceleration in its terms of trade from 2003 , driven by rapid increases in the world prices of its minerals and energy exports. The resulting significant real appreciation of the Australian dollar damaged the country's international competitiveness, and Australian manufacturers, tourism operators and exporters of education services suffered. But the narrative of Australian mercantilism couldn't explain what was going on.

I F THE term 'international competitiveness' is to prove useful for Australia's place in the Asian century, then it will have to be framed in terms of Australia's national endowments and capabilities-a framing compatible with neoclassical theories of comparative advantage. A narrative with this framing should be capable of explaining how exploiting these endowments can help achieve a vision of a future Australia in the Asian century as a prosperous and secure nation, with sustainably rising living standards and quality of life, that is integrated into this diverse region and open to the world.

Australia remains in relatively good shape. Unlike most of the rest of the developed world, government balance sheets are strong. The financial system is sound. Australia's economic policy frameworks and governance institutions, developed over several decades, insulated the Australian economy from the external shocks associated with the Asian financial crisis of the late 1990s. These frameworks and institutions represent 'created endowments' - a legacy from an earlier generation of Australians.

Australia's natural endowments, too, have a strong measure of complementarity with the world's fastest growing economies. Australia has large environmental assets, abundant mineral and energy reserves and the capacity to produce greater volumes of high protein foods. And in this Asian century, Australia has locational advantage.

Australia's human capital endowments are also significant. It has a highly skilled, diverse and creative population that has demonstrated capability in innovation, design and complex problem solving. Peopleto-people ties with the region are growing deeper, as migrants, students and visitors from Asia bring new perspectives, energy and skills. Australians also increasingly live, study and work in the region.

But it would be a mistake to think that Australia has done all it needs to do. Indeed, the challenge for government, business and the community is immense. A new mindset is required. Success in this century means a willingness to adapt continually.

Prosperity will come from Australia building on its strengths, reinforcing the domestic foundations of society and a productive, open, flexible and resilient economy. This involves investing across the five pillars of productivity—skills and education, innovation, infrastructure, tax reform and regulatory reform.

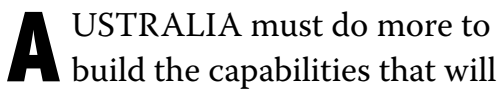
help it succeed by investing in its people's education and skills. Highly innovative, competitive Australian firms and institutions should develop collaborative relationships with others in the region. Australian governments need to be involved in initiatives that make the region more open and integrated, encouraging trade, investment and partnerships.

With its country's future irrevocably tied to sustainable security in the 
region, Australian governments should continue to support a greater role for Asian countries in a rules-based regional and global order. And the deep and broad relationships that already exist across the region should be strengthened at every level. These links are social and cultural as much as they are political and economic. Engagement to date has been episodic; Australia needs to adopt a more strategic approach to bilateral relationships.

1 HE 21st-century recipe for longterm business success comes from working collaboratively with partners in Asia, not just competing against them. In some cases, Australian businesses will be able to

\section{Australia must do more}

to build the capabilities

that will help it succeed

by investing in its

people's education and

skills. Highly innovative,

\section{competitive Australian}

\section{firms and institutions}

should develop

collaborative relationships with others in the region. access large Asian markets through export, including as part of regional supply chains. In other cases they may establish enterprises, including business partnerships, in Asian countries. Australian businesses will need the capabilities to do both.

'Collaboration' and 'engagement' are part of the language of this century, just as 'international competitiveness' was the language of the last quarter of the last century. The central point here is that gains from trade arise not from mimicry but from harmonious points of difference that allow for complementarity. Australia's include: exceptional standards of corporate governance and workplace safety; an insistence on quality, including

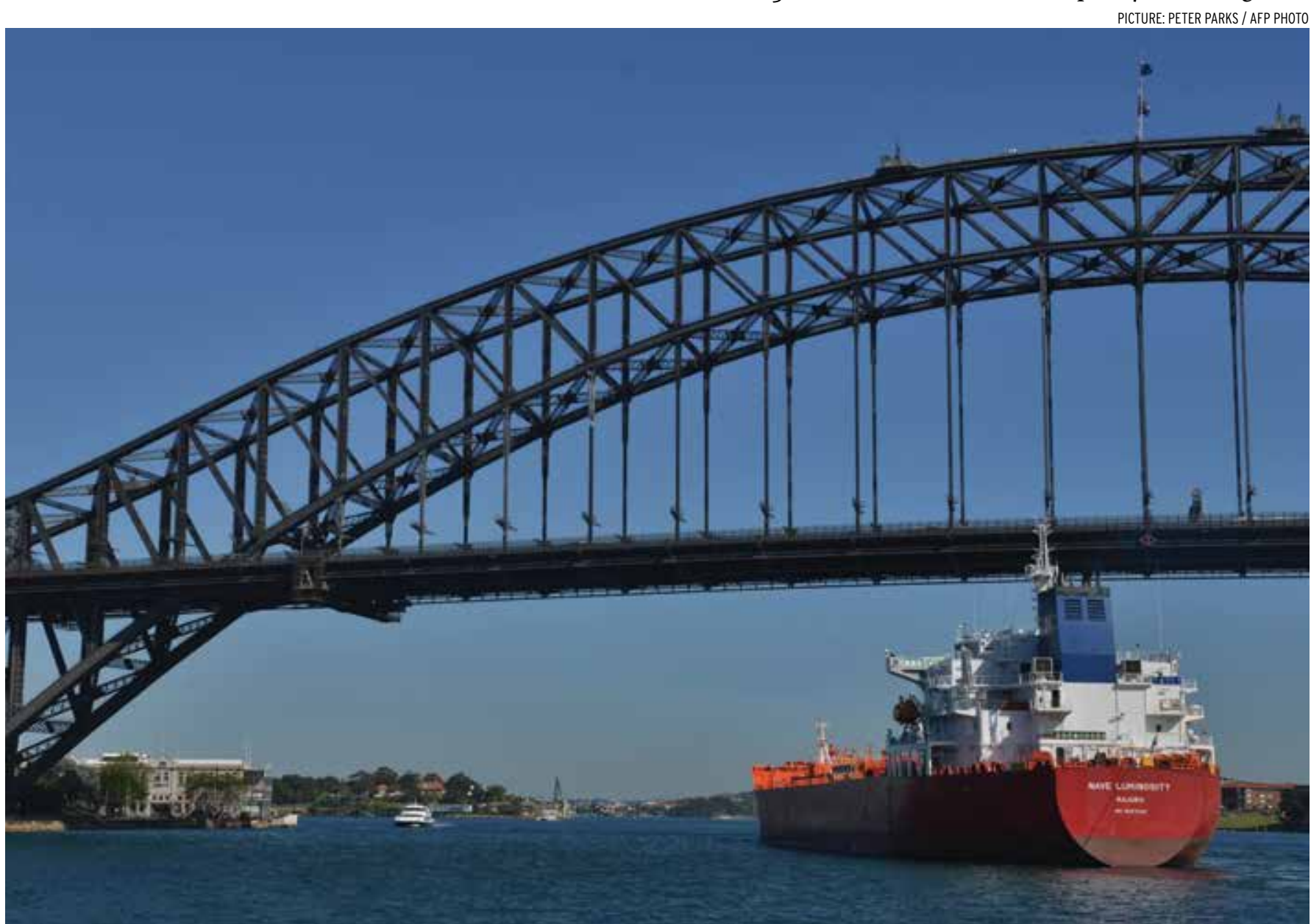

A trading ship arrives in Sydney Harbour on 6 October 2015. Asian nations able to engage and work collaboratively with international partners to supply the region's burgeoning markets will be the ones to prosper in the coming century. 


\section{THE GFC HANGOVER}

with respect to food standards and animal welfare; and an intolerance of corruption.

For Australian businesses and individuals that develop the capability to engage in this way, there is a vast landscape of new opportunity, especially in supplying goods and services to an increasingly prosperous Asia and in ventures to help address the challenges confronting several large regional neighbours in respect of water security, energy security, food security, green growth, urban design, health care and aged care.

B UT only a small proportion of Australia's population has these capabilities at the present time. What is needed is Australians with the knowledge and skills to develop strong relationships in the region; with the capacities to understand and operate in cultures, languages and mindsets other than their own. Australia needs comprehensive partnerships involving government, business, community organisations and citizens generally, through commerce, institutions, travel, arts, culture and sport, as well as education, ideas and knowledge exchange.

The focus on capabilities informs a more sophisticated understanding of international competitiveness and a more relevant economic reform narrative than that of Australian mercantilism-one which comprehends the role played by national endowments, both natural and created, in driving national performance. EAFQ

Ken Henry is a non-executive director and Chairman Elect of the National Australia Bank. He served as Secretary to the Australian Treasury from 2001 to 2011. In 2012 he led the development of the White Paper on Australia in the Asian Century.

\section{Facing up to the long-term fiscal challenges}

ALAN J. AUERBACH

$\mathbf{T}$ HE global financial crisis (GFC) that precipitated the worldwide great recession in 2008 has largely subsided. Capital markets are generally operating smoothly, liquidity has been restored and new initiatives toward financial regulation are aimed at reducing the likelihood of recurrence. But in other respects the effects of the crisis live on. Many leading economies are struggling to regain adequate levels of economic growth, even with historically low (in cases even negative) government interest rates. Moreover, large government budget deficits during the recession, attributable to the economic weakness itself as well as expansionary fiscal measures aimed at combating it, have left many advanced economies with much larger levels of national debt than they had just a few years earlier.

In confronting many remaining and serious economic challenges, advanced economies face greater fiscal pressure. This pressure comes not only from elevated debt-to-GDP ratios, which have received considerable attention, but also substantial and largely unrelated fiscal challenges over the longer term. These can be attributed to demographic change, the rising cost of age-related social insurance and other spending programs. While focusing on managing the short-term debt burden may help avoid crises like the one being played out in Greece, attention and policy actions must eventually turn to the longer-term fiscal problem.

Estimates of current-policy fiscal trajectories among the world's advanced economies can be used to evaluate their long-term fiscal sustainability. Studying these economies, it is quite evident that though the short-term fiscal measures used in many countries, such as the debt-to-GDP ratio and the current budget deficit as a share of GDP, may in some cases be reasonably good indicators of long-run sustainability, as for Australia and South Korea, for example, they bear little relationship to the sustainability of policy for many others. This is true for Italy and Greece, which appear to be on relatively sustainable paths despite challenging short-run statistics, and for Japan and the United States, for which worrisome short-run measures nonetheless understate the magnitude of long-run challenges. While one may be able to discount our negative long-term projections due to the uncertainty involved in such forecasts, based on the demographic transition that is underway, one cannot ignore their general negative direction.

ANY advanced countries face $M$ fiscal challenges that-rather than primarily evolving from prior debt obligations-concern future obligations, with an increasing impact on primary deficits. These obligations are primarily associated with the cost of providing pensions 


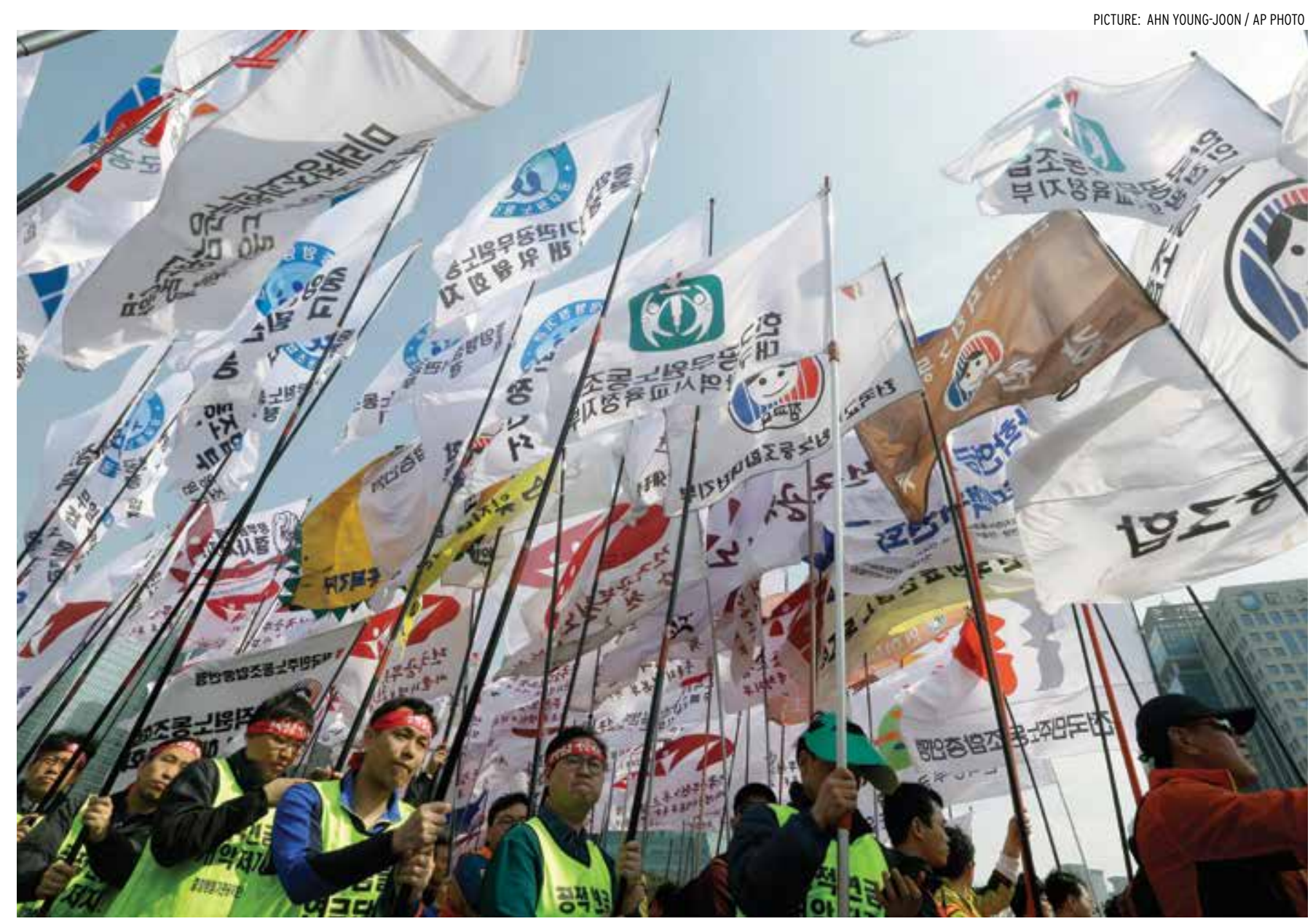

Unionised civil servants hold their union flags during a rally to oppose the government's bid to overhaul the public pension system near the National Assembly in Seoul, South Korea, Saturday 28 March 2015. South Korean President Park Geun-hye called for parliamentary endorsement of a bill meant to reform the pension system for civil servants in the latest appeal to reduce the government's growing pension deficit.

and healthcare in the face of growing old-age dependency ratios. These 'demographic and health' deficits present a number of challenges to the formulation and implementation of future fiscal adjustments.

Standard budget control rules and other related mechanisms do not integrate longer-term adjustments in such 'implicit' liabilities and so exert less pressure for undertaking these adjustments. There is also enormous uncertainty about the magnitude of these implicit liabilities, which makes the politics of adjustment more difficult, even though increased uncertainty about future costs should, in principle, lead to even more budget stringency to avoid outcomes that are socially very costly.

There is also no simple formula for adjustment. Countries vary with respect to the severity of their imbalances, the composition of their imbalances and their fiscal capacity to absorb additional tax increases rather than relying on reductions in spending. The recent literature on fiscal consolidation has focused especially on tax increases versus expenditure reductions, but dealing with longer-term fiscal gaps requires a different focus. For example, given their importance as a source of fiscal gaps, reform of pension and healthcare systems is clearly a central agenda item for many advanced countries.

OME countries, such as Italy, have already introduced pension reforms in recent years and face much lower fiscal gaps as a result-if these pension reforms can be sustained. Healthcare reform is a more complex issue. It does not simply deal with a system of taxes and transfers but also with the structure of a very large and complex series of markets and the incentives associated with their operations. This means that even with expenditure reforms, rising expenditures as a share of GDP may be inevitable, making tax increases a necessary condition for fiscal balance. But with a longer planning horizon tax 


\section{ASIA'S AGEING POPULATIONS}

increases can take a variety of forms, including opening the possibility of more structural reforms which are more efficient than simply increasing marginal tax rates.

INALlY, fiscal gaps that are attributable to large implicit liabilities are not easy to deal with through traditional budget control mechanisms that focus on explicit debt and short-term deficits. Indeed, policies to deal immediately with long-term fiscal gaps could over the short term result in large, though temporary, budget surpluses (in order to accommodate longer-term spending growth). The ability of the political process to sustain such surpluses is certainly questionable.

These challenges require new approaches to budget control. One such measure would be to introduce or strengthen the role of independent fiscal councils or budget authorities. These institutions could improve transparency, expose gaps in logic and provide support for needed changes in fiscal policy that may require implementation over a number of years.

HE great recession left nearly all advanced economies with substantially higher debt-to-GDP ratios and in many cases with lingering economic weakness that further complicates short-term efforts at fiscal consolidation. But the longer-term challenges these countries face are in many cases related much more to the future fiscal challenge of growing primary deficits, associated with the cost of providing pensions and health care in the face of growing old-age dependency ratios, and not simply reducing overall debt. EAFQ

\author{
Alan J. Auerbach is a professor of \\ economics and law at the University \\ of California, Berkeley.
}

\section{Growing old before growing rich}

PETER MCDONALD

$\mathbf{T}$ HE 21st century will be one of ageing populations. This phenomenon is well underway in all Asian countries as a result of the spectacular falls in both fertility and mortality rates in the second half of the 20th century.

These demographic changes date back to initiatives from as early as the 1950s. Influential arguments from the time viewed rapid population growth as an obstacle to development, and countries across the region pursued policy measures to reduce fertility rates.

In a study of 14 Asian countries, all but two (Japan and Australia) had high fertility of between five and eight births per woman in the early 1950s. By 2005-10, only two countries, the Philippines and Pakistan, had a fertility rate above three and, in both cases, fertility was trending downwards strongly. Evidently, the campaign to reduce fertility rates in Asia has been remarkably successful.

But the speed and timing of the decline in fertility has varied across countries. In India, for example, the decline started in the early 1960s but has proceeded slowly. On the other end of the spectrum, the decline in Iran started in the mid-1980s but was spectacularly fast. Generally, the falls in the Southeast Asian countries proceeded more slowly than in the East Asian countries with Thailand being on the faster end and the Philippines on the slower end. Pakistan has been a late starter, with fertility not falling until the 1990s. But, since then, the decline has been strong.

In five of the countries studied (Japan, South Korea, China, Singapore and Thailand), the fertility rate now sits at very low levels of under 1.5 births per woman. Combined with previously high fertility rates, this will produce large increases in the population at older ages.

NCREASES in life expectancy

have also been spectacular. Life expectancy at birth exceeded 65 years in only one of the countries (Australia) in 1950-55, but it did so in all 14 countries by $2005-10$. This was achieved initially through the eradication of deaths from infectious diseases and more recently through control of degenerative diseases especially heart diseases.

As life expectancy rises, countries are facing substantial increases in the demand for aged care and health services and income support for elderly people. This is a considerable problem for those countries where ageing is occurring rapidly in the absence of policies and programs to address these challenges.

Australia and Japan have had many years to develop such policies. Singapore has policies for an ageing population in place, but still also faces a significant problem because of its very low fertility rate. For the other 11 countries, aged care and income support policies are, at best, in an embryonic state and health systems are not well prepared.

At the same time as populations in Asia will be ageing rapidly, numbers entering the labour force at younger 


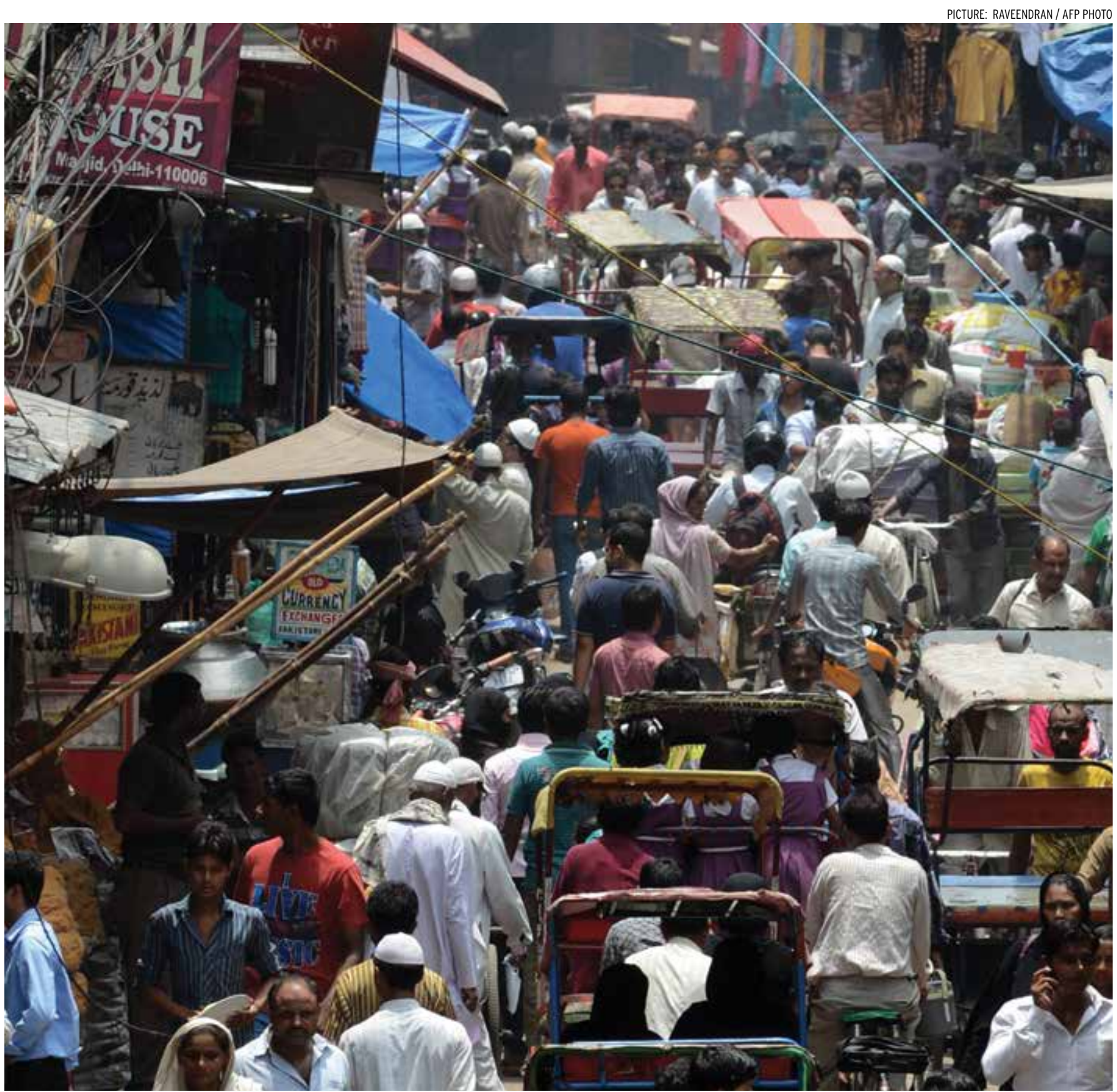

Indian commuters travel through a market area of New Delhi on 10 July 2013, on the eve of World Population Day. Africa and Asia are the continents that will see the fastest urban population growth in the next 40 years according to the UN.

ages will be declining. This will be a greater problem for those countries that have experienced rapid and substantial fertility decline compared to those where the decline was more gradual.

The trends in labour supply can be seen by looking at the ratio of projected number of persons aged 15-24 years in 2050 compared to the number in the same age group in 2010. For China, this ratio is 0.57 meaning that the number aged 15-24 in 2050 (139 million) will be 43 per cent lower than the number in 2010 (242 million), a fall of over 100 million in the labour force entry ages.
In 2050, the numbers aged 70-74 in China will be larger than in any other age group and the numbers taper down across all the labour force ages. So, not only will the labour force in China be much smaller, it will also be much older.

Immigration cannot be a solution to these labour shortages given that 
China's population base is so large. China will likely have to look to investment in other countries that will have large labour supplies (India, Indonesia or several Sub-Saharan African countries).

For seven of the 14 countries, the fall in the size of the labour force entry age group is more than 80 per cent with the falls in Thailand and Vietnam being similar to that of China.

The fall is not as large in Japan between 2010 and 2050 as China. Still, the labour force will fall year upon year and will age further in coming years.

The challenges ahead for the Japanese economy are probably greater than has been the case in the past two decades.

The demographic situation is somewhat better in the Republic of Korea because very low fertility is a relatively recent development. Fertility has been below 1.5 births per woman in Singapore for about 20 years, but Singapore has addressed this demographic problem through large- scale immigration. This is a possibility for a small country as the number of migrants involved is reasonable.

In India and Indonesia, the number of persons aged 15-24 years in 2050 will be roughly the same as in 2010 . Provided their young people are well educated, India and Indonesia should have a labour supply advantage over the next 40 years. In the Philippines, the population aged $15-24$ in 2050 will be 35 per cent larger than in 2010 . We can expect the Philippines to continue to be a major supplier of labour around the globe.

Finally, with a 44 per cent increase in the population aged $15-24$ over the years from 2010 to 2050, Australia stands out as a country with a growing supply of young workers. This is because its fertility rate has continued to remain close to the replacement level and because of its sustained immigration program.

A number of countries (Malaysia, India, Bangladesh, Indonesia and the
Philippines) are projected to have a 'beehive' shaped age structure by 2060. This is generally considered to be a favourable age structure with a relatively high concentration of population in the working ages. The issues for these countries will be more economic than demographic with a strong need to improve labour productivity through education and training.

NDIA and Pakistan will have

huge growth in the working age population from 2010 to 2050 .

Growth in the labour supplies of India and Pakistan are easily enough to compensate for the combined falls in labour force in the advanced countries of Asia and Europe. And out-sourcing of jobs to South Asia will be a growing feature of 21st century Asian economies. EAFQ

\section{Peter McDonald is professor of demography at the Crawford School of Public Policy, at the ANU.}

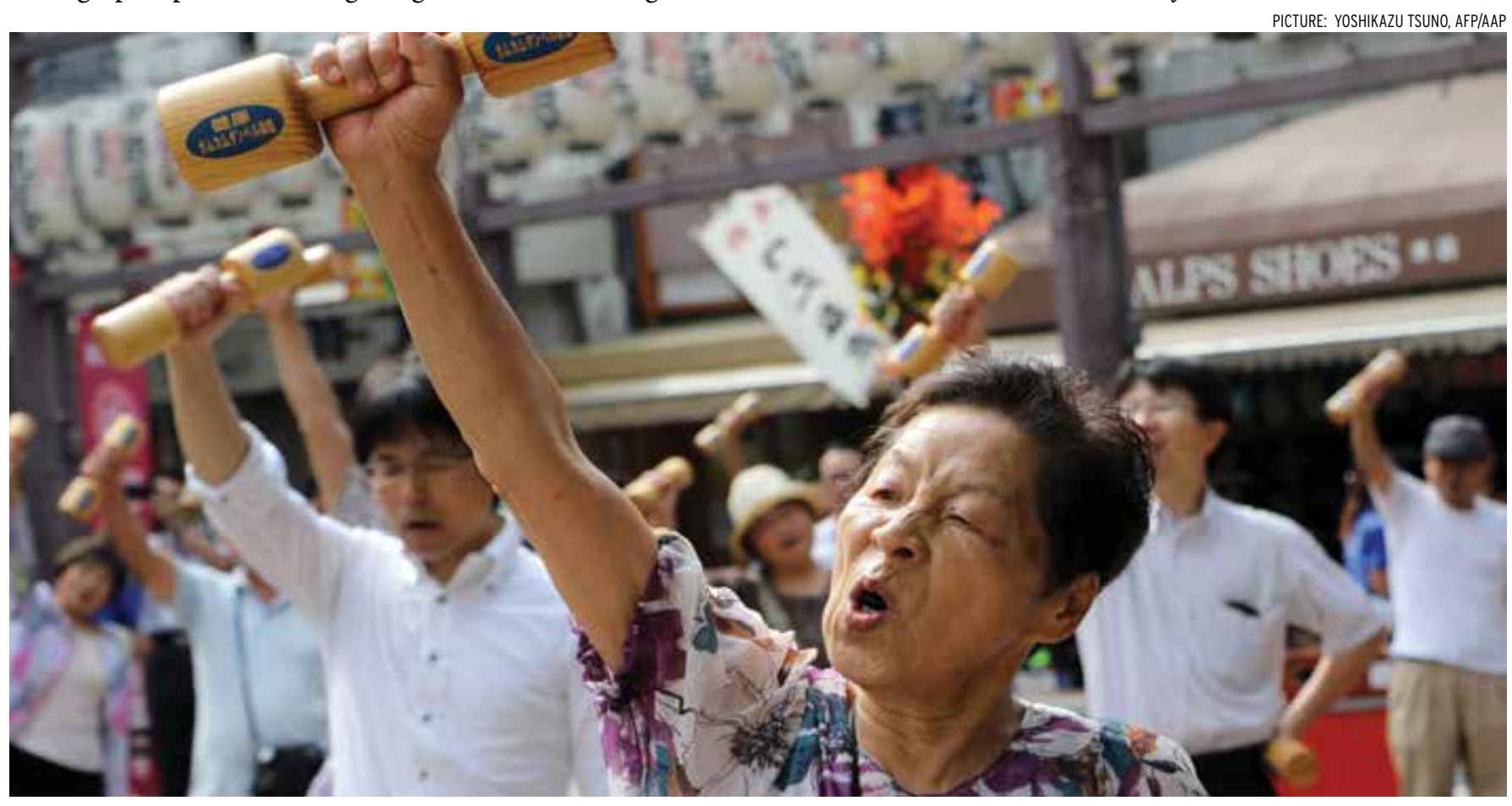

Elderly people work out with wooden dumb-bells in the grounds of a temple in Tokyo on 21 September 2015 to celebrate Japan's Respect for the Aged Day. 


\section{A new age of Chinese growth}

\section{CAI FANG AND LU YANG}

HINA saw a 9.8 per cent growth

rate on average during 1978-2010, higher than in any other country. China will likely surpass the United States to become the world's largest economy in purchasing power terms this year, if it has not already done so.

So how long can the boom last?

China's economic growth has been slowing down considerably. Forecasting economic growth into the future is an inexact science. Simply extrapolating past trends is unlikely to give accurate predictions, especially if it does not take into account the different stages of development through which economies move. Studies that take account of 'catch up' growth and benchmark China to the experience of other East Asian nations suggest that China still has the potential to grow quickly. But this sort of analysis does not allow us to examine the deeper structural factors that influence the growth rate.

In China's case, the specifics of the demographic transition now underway must be considered. For instance, if we use the peak workingage population and the turning point of the dependency ratio (which measures how many non-working-age people there are for every workingage person) as a benchmark, China is where Japan was in the early 1990s. Thereafter, Japan's annual average GDP growth has been less than 1 per cent.

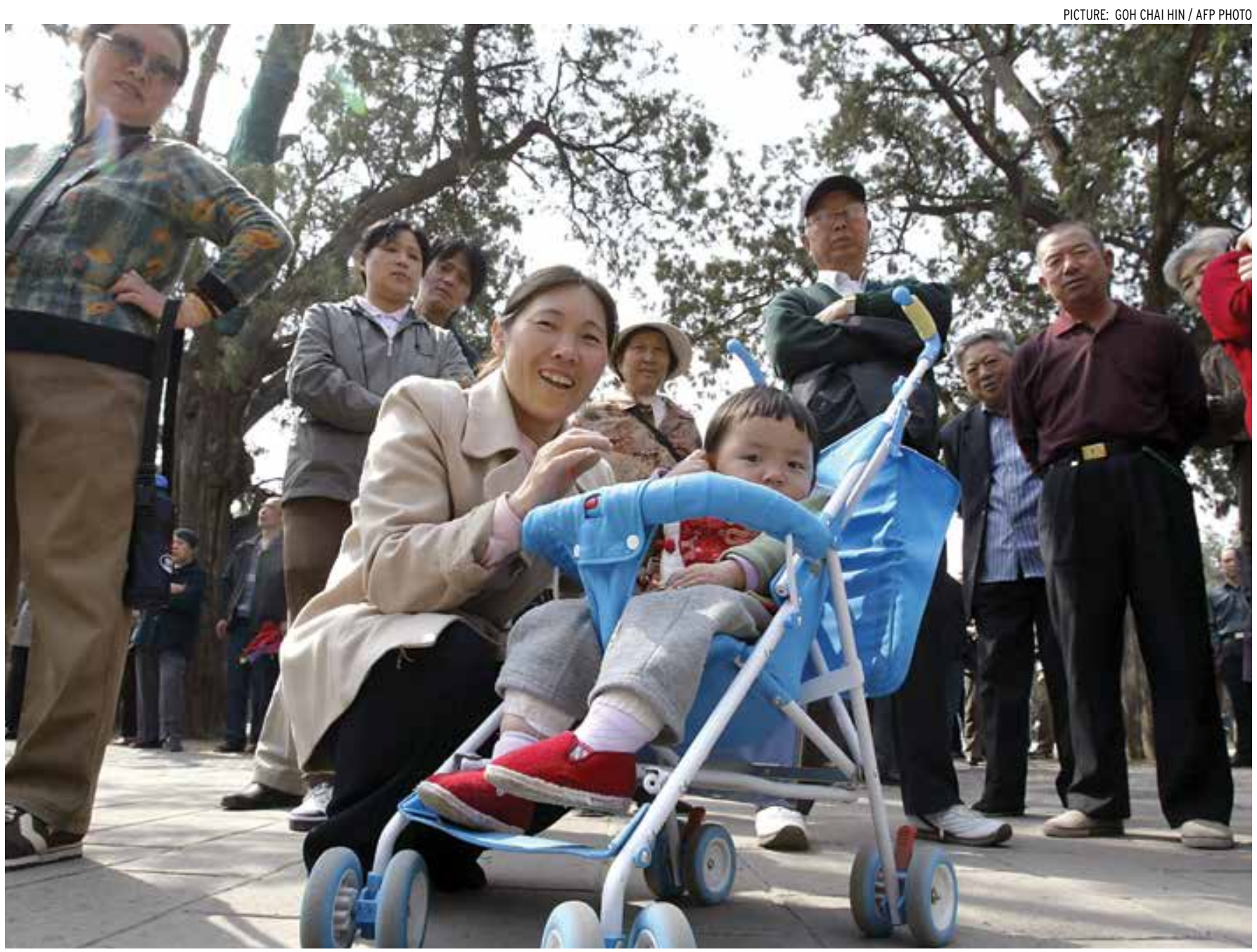

A young Chinese boy sits in his stroller surrounded by a group of adults at a park in Beijing on 16 April 2004. The end of China's demographic dividend makes its contemporary growth paradigm unsustainable. Productivity increases will need to replace expansions in factor inputs to secure long term growth. 
In the early days of the reform period, China's family planning policies accelerated the process of demographic transition by increasing the working-age population and lowering the dependency ratio: the so-called 'demographic dividend'. Under China's 'one-child' policy China's total fertility rate-that is, the number of children an average woman has in her life-has dropped to 1.4 , well below the rate required to keep the population stable. This policy has stabilised the population, and delivered an unprecedented sizeable growth dividend. But China's working-age population peaked in 2010 , and the population dependency ratio has begun to increase.

A significant portion of the unprecedented economic growth in China over the past 30 years-as much as one-quarter of all growthcan be attributed to the demographic dividend. Two mechanisms behind this phenomenon are the lower dependency ratio, which leads to a higher rate of capital formation, and the fast growth in the working-age population, which leads to a higher labour supply. Both of these are contributing to higher economic growth.

B UT the reversal of demographic trends means that China's traditional growth model will become unsustainable. At current fertility rates, the contribution of the demographic dividend to growth will be close to zero in the next few years. And after 2020 demography will impose a burden, rather than a boost, to growth.

So what can be done?

Broadly speaking, possible reform measures can be classified into two categories. The first would aim at prolonging the demographic dividend. The second would seek to improve China's productivity performance.

C HINA'S total fertility rate is - certainly low. And, at 1.4 children per woman, it is close to the "low fertility trap' level of 1.3 children per woman below which it has historically been impossible for countries to return to replacement levels of fertility. Fertility can be increased by relaxing China's family planning policy. But China's new policywhere a family in which either parent is an only child is permitted to have a second child-has had only a limited effect on fertility. Relaxing policy on family size will generate different short-term and long-term growth effects, lowering growth in the short term and raising it in the long term. China will move sooner rather than later to an unrestricted 'two child policy'.

Raising the retirement age could also put off China's demographic headwinds. But this is unlikely to have a very strong or a long-lasting impact on China's potential growth. Increasing educational attainment could yield a moderately large dividend: one additional year of schooling on average for Chinese

\section{Another important}

productivity-raising step

should be to reform

\section{China's household}

\section{registration system}

to make it easier for

workers to move to jobs

in which they will be most productive. citizens would lift China's potential growth rate from 6.6 to 7.5 per cent from 2016 to 2020. But the impact of this would tail off over time. Increasing the quality of education could also have significant impacts on growth potential.

But the real potential for sustaining Chinese growth is in improving productivity. In many sectors, technology has yet to catch up to the level of the advanced economies. And given the large disparities in productivity among firms within sectors, there should be regulatory reform to make it easier for workers and capital to shift from low-productivity firms to high-productivity firms. This would allow more efficient enterprises to expand and develop, while inefficient enterprises are driven out of the market. Strengthening market mechanisms in China is essential to boosting productivity and hence growth.

Financial system reform is also essential to raising productivity, with interest rate liberalisation a top priority. Only market-based interest rates can efficiently allocate resources and hence drive productivity.

(2) HINA is entering a 'new normal' of economic development.

Understanding the demographic drivers of growth so far is essential if China's leaders are to steer the economy through the challenges that lie ahead. EAFQ

Cai Fang is vice president and professor at the Chinese Academy of Social Sciences, Beijing.

Lu Yang is associate professor at the Institute of Population and Labor Economics, Chinese Academy of Social Sciences, Beijing. 


\section{Japan's race against the ageing clock}

\section{ATSUSHI SEIKE}

$\mathbf{T}$ HE ageing of Japan's population is globally unprecedented both in its level and its speed.

The proportion of people aged 65 years old and over is now more than one-quarter of the total population of Japan-proportionally, the largest in the world. This will grow to one- third of the total population in 2035. It took only 24 years-from 1970 to 1994-for the proportion of Japanese people aged over 65 to increase from 7 per cent to 14 per cent. In European countries it took at least $50-100$ years. Japan's population has aged twice as fast as Germany's and more than four times faster than France's.

Even this understates the scale of the challenge. Not only are there proportionally more people over the age of 65 , but the population over 65 is getting older. The proportion of people aged 75 years and over is increasing particularly rapidly, and is expected to reach 20 per cent of Japan's population in 2035.

This ageing population has an enormous impact on Japan's economy

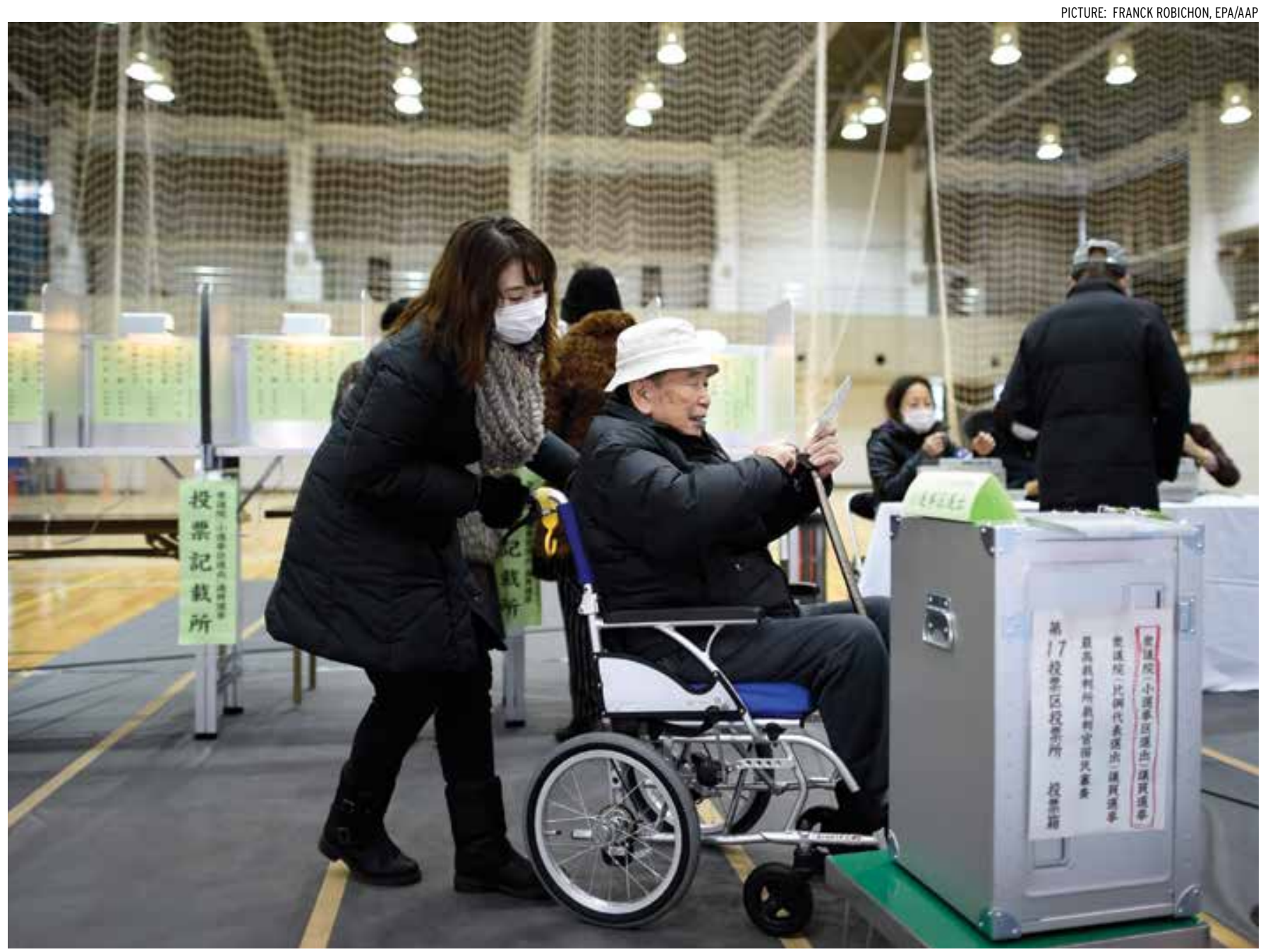

An elderly Japanese man on his way to cast a vote in 2014. The proportion of people aged 65 years old and over is now more than one-quarter of the total population in Japan—proportionally the largest in the world 
and society. Its most significant impact is on social security. As a result of this ageing population, total spending on social security was almost 110 trillion yen (approximately US $\$ 924$ billion) in the 2012 fiscal year-22.8 per cent of GDP.

APAN will have to make do with a smaller workforce. Productivity will have to increase if Japanese people are to enjoy the same living standards.

Japan should take every possible measure to cope with an ageing population. One step is of course to reverse the decreasing fertility rate. But even if the fertility rate recovered drastically, it would not make much difference to the dependency ratio, because newborns would not enter the workforce for some decades. Japan must therefore promote the employment of older people.

If older people with the will and ability continue working beyond the current retirement age, it will reduce the average per capita burden of the ageing society. The increase in the number of active workers and consumers in their old age would be a driving force of economic growth on the supply side as well as the demand side of the economy.

But Japan faces several obstacles that prevent it from promoting higher labour force participation among older people.

One obstacle is the public pension system. Any pension system will naturally make retirement more financially attractive to older workers. Japan's current system includes strong incentives for pension-age Japanese workers to retire or to reduce their working hours, including an earnings test that lowers the pension rate the more you work. Japan should consider reforming pension eligibility to improve work incentives.

Mandatory retirement practices are still dominant in Japan. While having mandatory retirement from one's primary job need not entail full retirement, in practice it often does. In Japan mandatory retirement reduces the probability of men aged 60-69 participating in the labour force, all other things being equal. Mandatory retirement also tends to push workers who stay in the workforce into jobs where their acquired skills and knowledge are underutilised, leading to a loss in productivity.

But if Japan revises mandatory retirement practices by lifting the legal minimum age of retirement or by introducing anti-age discrimination legislation, it will also need to change the seniority-based wage and promotion system. If a firm lifted the mandatory retirement age while leaving seniority-based wages unchanged, it would have to raise its wage bill considerably. Tackling this will require cooperation between unions and employer groups.

Encouraging older Japanese people to stay in the workforce will only mitigate part of the problem. The social security system also needs urgent reform.

Benefits for young people should be more generous, particularly with

Japan will have to

make do with a smaller

workforce. Productivity

will have to increase if

Japanese people are to

enjoy the same living

standards. respect to childcare. In the late-1970s, when the fertility rate started declining, the Japanese government should have been concerned about population decline. But it took until the 1990s for the government to introduce the so-called 'Angel Plan'-a package of policies, which on the whole was not very daring, to promote comprehensive childcare support.

Unlike pensions, medical care, and long-term care-which are guaranteed revenue under Japan's social insurance system-childcare has historically not had any permanent revenue source. So in 2013 the National Council on Social Security System Reform, which I chaired, recommended that the government should reserve revenue from the consumption tax for childcare. OSTS in both the pension and $\checkmark$ in the medical and long-term care systems must also be contained. Changing the pension eligibility age will help with the former, but medical and long-term care spending will be somewhat more difficult to restrain. They will increase at more than the rate of increase of the older population. This is not only because people over 75 years old are more likely to need medical and long-term care, but also because of the increase in the quality and the cost of medicine and care. Addressing this problem will require cooperation with service providers.

Japan's high debt-to-GDP ratio means that social security system reform is vital. These reforms will face political opposition from both beneficiaries and service providers. Without them Japan will not be able to sustain a social security system that has enabled it to attain the highest longevity in the world. EAFQ

Atsushi Seike is president and professor of labour economics at Keio University. 


\section{Moving beyond marriage in Japan}

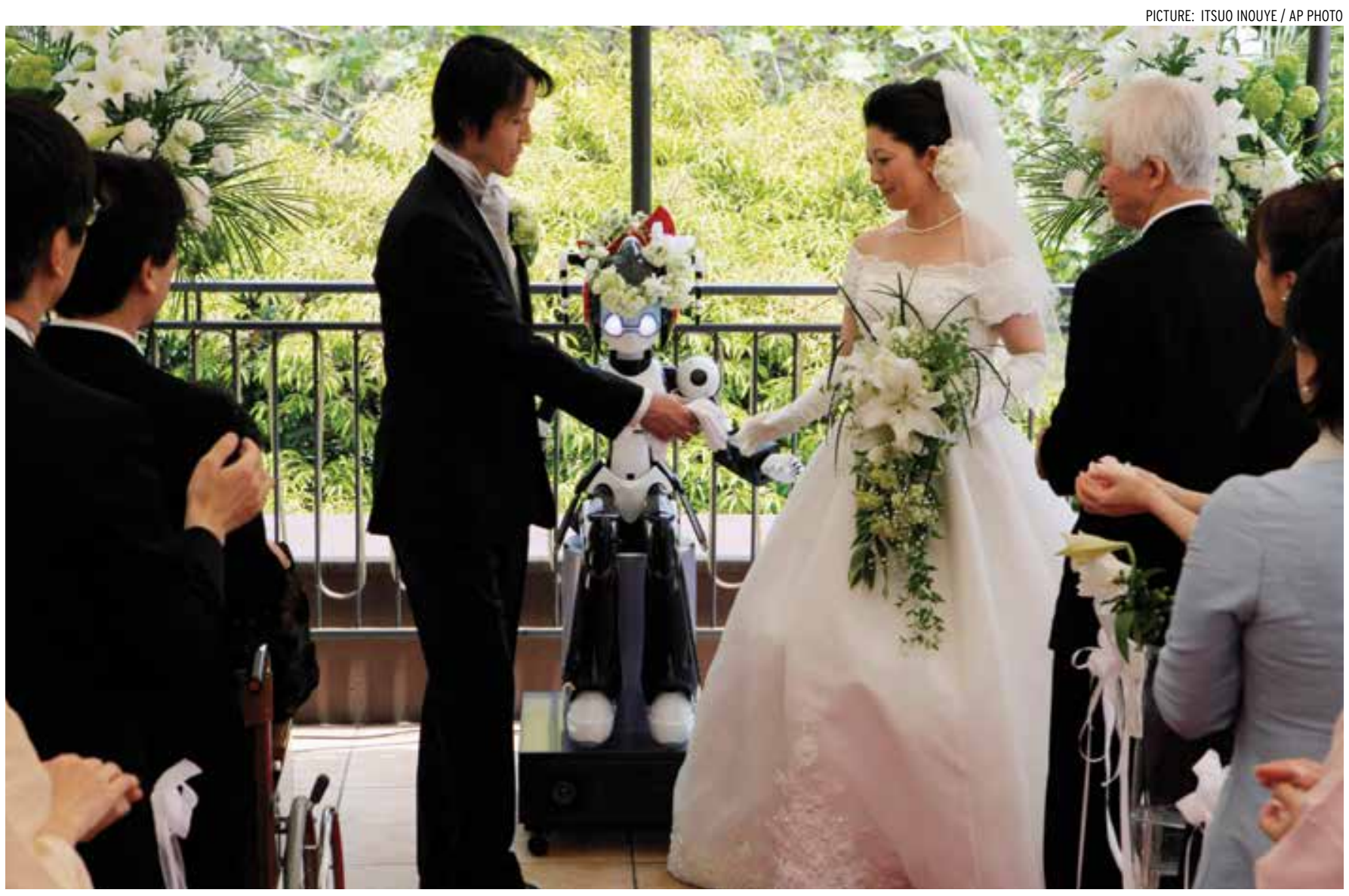

I-Fairy, a four-foot tall seated robot, directs a wedding ceremony at a Tokyo Restaurant in 2010. Marriage is no longer the universal norm it once was in Japan, with both Japanese men and women marrying later and less.

LAURA DALES

D ISCUSSIONS of sex in Japan typically spotlight the extremes of the social landscape: from the hypersexualised (2D girlfriends, hug cafes, erotic manga) to the sexless. Gender is skimmed with reference to 'herbivore men' and 'parasite singles'. But beyond the salacious and the superficial, sex and gender are topics that demand careful consideration from Japanese policymakers as well as scholars.
Issues of sex and gender matter because they sit at the heart of the demographic shifts that will shape the coming century for Japan. Sex, sexuality and gender reveal tensions that affect the lives of individual Japanese, and which consequently steer the economic and political direction of the country.

Marriage is no longer the universal norm it once was: in 1965 , only 1.5 per cent of men and 2.5 per cent of women remained unmarried at age 50. In 2010, these figures had jumped to more than
20 per cent for men and 10 per cent for women.

Japanese women and men are marrying later and less. Those who do marry are having fewer children than in the past, with an average of 1.96 'completed number of children' per married couple in 2010. Extramarital births account for just 2.4 per cent of all births, and 'shotgun weddings' have steadily become more common over the last two decades. It is clear that Japanese prefer to marry before having 
children, and so a decline in marriage means fewer babies.

Delayed marriage and non-marriage, along with attendant low fertility rates, have featured prominently in discussions of hyper-ageing and population decline in Japan. At a macro level, the economic implications of a diminished labour force and an overburdened aged care sector invite talk of labour migration, a prospect that has thus far been limited. But these demographic trends have also drawn attention to the needs of a population that increasingly diverges from the nuclear family norm of postwar Japan: the non-married adult.

$\mathbf{T}$ HE declining trend in Japanese marriage rates reflects socioeconomic barriers, such as economic insecurity and underemployment, as well as differing perceptions of marriage and marriageability between men and women. The qualities that make individuals marriageable and marriage-minded-along with the circumstances in which prospective partners meet-have shifted considerably since the post-war period. Arranged marriages (omiai), as well as workplace romances (shokuba kekkon), have led to couplings of full-time male workers and part-time female workers (who were often also full-time housewives).

But two decades of recession, economic insecurity and underemployment make the male breadwinner model untenable. Unable to support a wife-not to mention children-men working as non-regular or part-time (freeta) workers are increasingly priced out of the marriage market. According to the Ministry of Health, Labour and Welfare, in 200741 per cent of regular male employees between 15 and 34 were married, while the figure for irregular male employees was 11 per cent.

$\mathbf{0}$ NE way to address the problem of marriageability would be to remove this barrier for underemployed men: a revision of marriage roles that would see both paid and unpaid work shared more equally. This would require a revision of working conditions to allow both male and female full-time workers to engage in domestic and care work.

Prime Minister Shinzo Abe's 'womenomics' policy ostensibly aims to address gender barriers promoting greater full-time female labour force participation. But, as many have noted, the policy does not address the gendered inequality on which the system is based. It is still predominantly women who are corralled into a domestic caregiver role, supporting men who work prohibitively long hours in rigid corporate structures, with limited flexibility for leave or alternative work styles. There is little incentive for educated women who want a

There is little incentive for educated women who want a family to stay in the workplace, hence the failure of 'womenomics'

to successfully attract educated women to full time work. family to stay in the workplace, hence the failure of 'womenomics' to successfully attract educated women to full time work.

When care remains primarily women's responsibility, it is not surprising that for many women, the choice of having a career or having children is a mutually exclusive one. And what of those who do not marry?

It is likely that a large percentage of women that are currently unmarried will need to be financially selfsufficient in the future. But unmarried women experience a number of labour-market and non-market constraints. In addition to the gender wage gap, unmarried women are much less likely to own their dwelling than their married counterparts and more likely to live in private rental dwellings or with their parents at all ages.

IVORCED women with children are particularly vulnerable. Although the vast majority work, typically for more hours per week than their married counterparts, they do not tend to have greater earning levels than married women. While 90 per cent of single mothers are in the labour force, around 60 per cent of these live in poverty. And while marriage remains the safest economic choice for women who want children, the increase in single-mother households - a 55 per cent growth between 1993 and 2011-suggests that marriage is not a watertight guarantee.

The incentives to marry may be weaker for professional women. For professional women, like heterosexual men in regular employment, decreased social pressure to marry along with the increased convenience of urban life-where most goods can be bought and most needs outsourced-make marriage less 


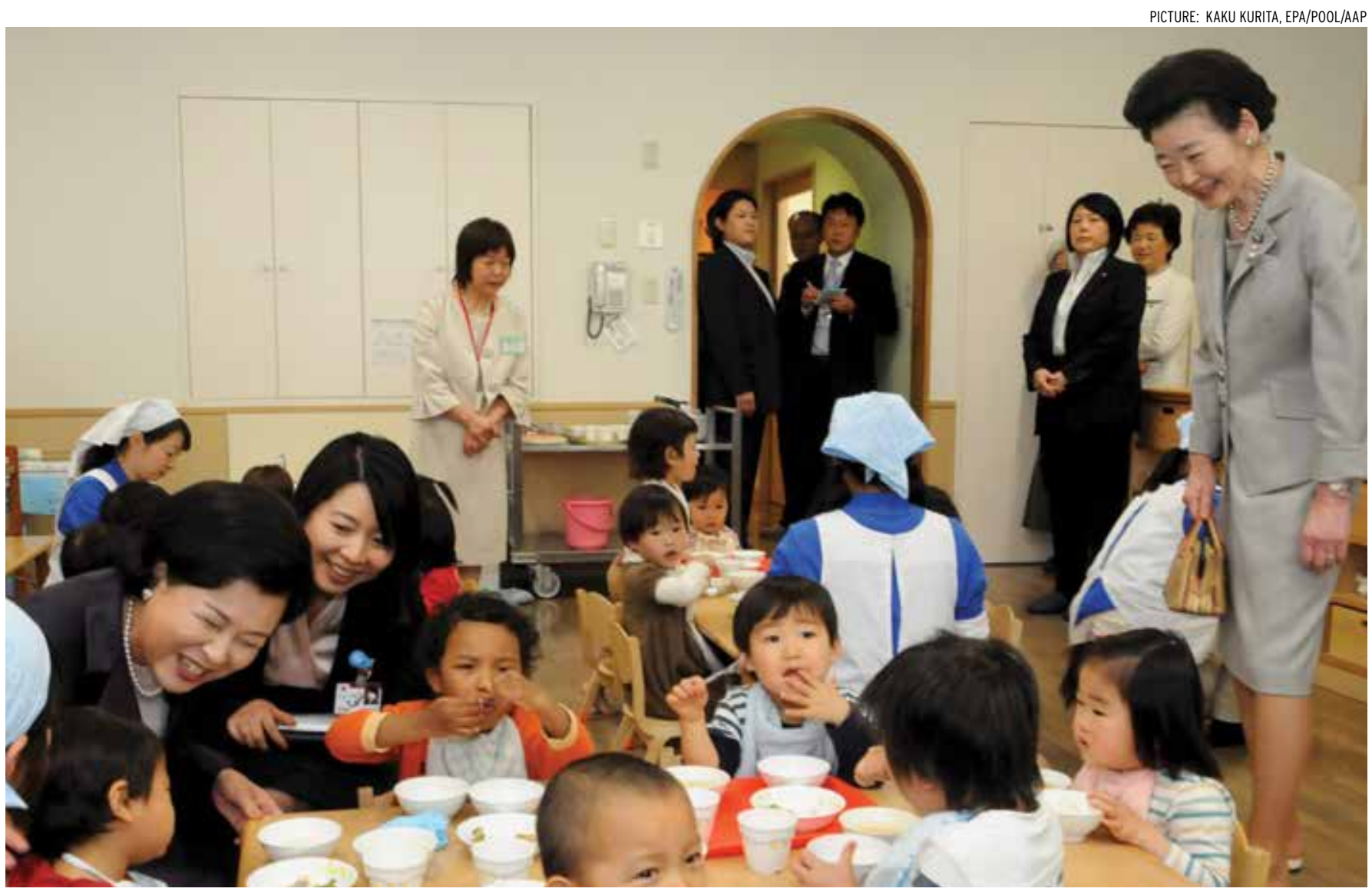

Then first lady of South Korea Kim Yoon-ok (L) and then first Japanese first lady Kiyoko Fukuda (R) talk with pre-school toddlers having lunch during their visit to Shibaura Island Children's Garden in Tokyo on 21 April 2008.

inevitable and possibly less attractive.

In light of a growing percentage of individuals who do not marry, the implications of other relationships become salient, for individuals and for the state. Discussion of samesex unions highlights just some of the ways in which the assumption of a universal life course centred on marriage produces (and reproduces) political inequalities that privilege particular versions of gender and sexuality.

N MARCH 2015, Tokyo's Shibuya

Ward Municipal Office became the first place in Japan to officially recognise same-sex unions. Passing an ordinance to allow it to issue 'partnership' certificates to gay couples, the Ward Office asked local businesses to recognise the certificates and accord equal treatment to the (adult) bearers. In June, Setagaya Ward Office announced it would follow suit later in the year.

The conservative Abe government is opposed to legislative reform on marriage. Prime Minister Abe has reiterated that the constitutional definition of marriage excludes same-sex couples and is based 'only on the mutual consent of both sexes' But as the first formal recognition of same-sex unions, the Shibuya ordinance suggests an increased public awareness, if not acceptance, of the rights of those outside the mainstream. This is also evident in increased corporate activity on LGBTIQ issues: employee training in diversity and gender sensitivity, sponsorship and participation in events like the Tokyo Gay Pride Parade.

C AME-SEX unions currently lack legal recognition, which means same-sex couples experience discrimination, such as the rejection of tenancy applications and hospital visitation rights. The lack of legal protection for same-sex relationships largely reflects the resilience of the koseki family registry as a fundamental legal and administrative structure. The koseki documents Japanese marital relations, parent-child relations and legitimacy, and ties individuals to members of a larger unit (the ko). Relationships that are not recognised (or recognisable) by the koseki are therefore legally and socially delegitimised. Those affected by 
this de-legitimisation include de facto heterosexual couples, foreign residents, same-sex couples, cohabiting friends and children born outside marriage.

7 HE increased visibility of same-sex relationships, and the obstacles inherent in the koseki, draws attention to the implications of gender and sexuality in contemporary Japan. State efforts to shape gendered roles and gender relations indicate the centrality of the household as an anchorpoint of neoliberalisation in the last decade. But the demographic changes described above may force the state to re-focus its gender ideology beyond marriage and the family.

Making non-marriage a supported and realistic life possibility requires policy support that extends beyond pronatalism to more fundamental gender equality. It needs something close to the definition given in Chapter One of Japan's 1999 Basic Law for a Gender-Equal Society, which aims for a society 'where both women and men shall be given equal opportunities to participate voluntarily in activities in all fields as equal partners in the society, and shall be able to enjoy political, economic, social and cultural benefits equally as well as to share responsibilities'

While marriage continues to feature in the life course of most Japanese women and men, it is only one possible lens through which to understand intimate adult relationships. For never-married, queer, divorced and widowed Japanese, non-marital-and nonfamilial-relationships offer scope for well-being and belonging. For this growing population, there is a critical need for policy initiatives that support new possibilities for housing and care, particularly for the elderly and the economically marginalised. Share houses, cooperative housing and LGBTIQ friendly aged-care are examples of housing arrangements that cater to those outside the nuclear, reproductive family.

Far from being marginal concerns, gender and sexuality are central to the socio-political landscape of contemporary Japan. The decline in marriage demonstrates that institutionalised constraints have a significant effect on labour force participation and on fertility levels. From a purely pronatalist perspective, there are good reasons to encourage a reduction in the gender divide on employment, care work and childrearing.

But even more significantly, there is a need to strategically address the growing population of incidentally

The increased visibility of

same-sex relationships,

and the obstacles

inherent in the koseki,

draws attention to

the implications of

gender and sexuality in

contemporary Japan. and intentionally unmarried women and men, as well as those who do not have children.

One common thread between the decline in marriage and the increased visibility of same-sex relationships is that both challenge notions of universal gendered norms like the full-time housewife and the regular salaried worker. The increasing number of Japanese who are not in heterosexual married relationships and do not have children challenges the state's investment in these households. Government initiatives to address the needs of these individuals must move beyond the assumption that marriage and children will inevitably and uniformly frame the lives of the Japanese citizenry.

These demographic trends are critical questions for policymakers grappling with a subdued economy, a resiliently gendered gap in employment patterns and an inevitable population decline.

D UT rather than construing current demographic trends as symptomatic of the decline and doom of Japanese society, it is possible to see them as an opportunity to invent new traditions of community that extend beyond the nuclear, reproductive family. Considered attention to the needs of the increasing number of people who do not marry, or do not remain married, invites a broader conceptualisation of what it means to be a Japanese woman or man in the 21st century. Flexibility of this kind will only benefit a state and society in demographic flux. EAFO

Laura Dales is a lecturer in Asian Studies at the University of Western Australia. 


\section{What happens when the king's gone?}

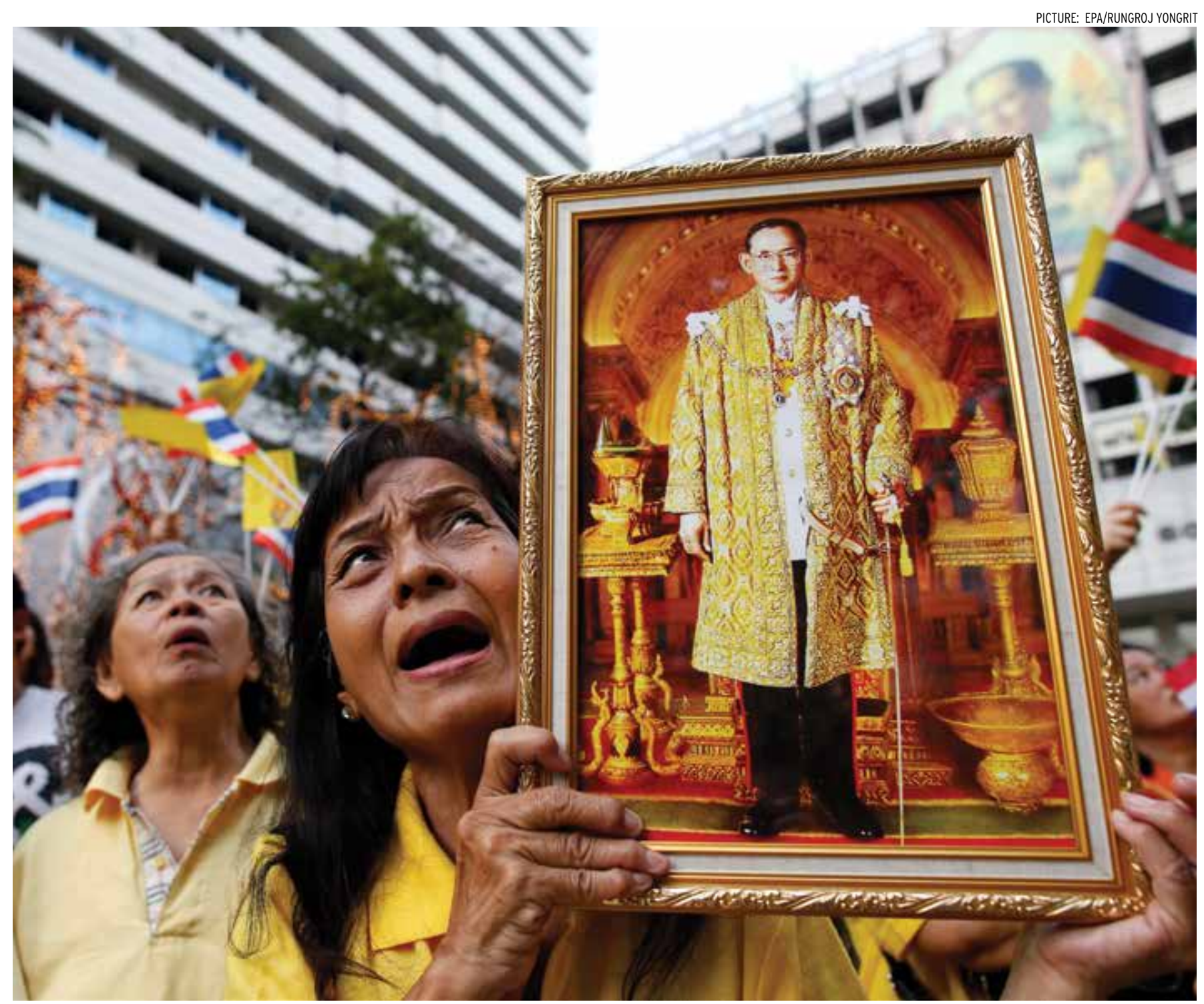

A Thai royalist holds a portrait of King Bhumibol Adulyadej as she shouts 'Long Live the King' to celebrate his 87th birthday at Siriraj Hospital in Bangkok, Thailand on 5 December 2015. A scheduled public appearance was cancelled due to health concerns.

NICHOLAS FARRELLY

D ACK in February 2005, Thaksin

D Shinawatra's Thai Rak Thai was re-elected with a bumper majority. His telecommunications fortune, cultivation of provincial powerbrokers and knack for televised theatrics made him the most popular, and electorally successful, politician in Thai history. His mandate as 'CEO Prime Minister' was to keep the economy bouncing along while restoring a dented national pride. Thaksin and his allies sought to make Thailand the destination for all that was great, good and prosperous in Southeast Asia.

As Thaksin consolidated ever 
more power, his opponents became anxious. The Democrat Party worried that it would never again control the levers of government, perpetually relegated to bridesmaid status as the outspoken telco billionaire effectively monopolised the political process. His influence on military and bureaucratic promotions hinted that he would not stop until all key positions were held by his trusted aides. In a system where there was already a well-established and deeply conservative culture of patronage, his audacious moves were upsetting the rambutan cart.

N THE lead up to the 2006 coup Thaksin was targeted by a chorus of self-righteous outrage. Groups that judged they would continue to miss out on the trappings of authority made it clear they could no longer tolerate his re-arrangement of the bureaucratic furniture. Cries of vote-rigging, policy corruption and abuse of power echoed from protest megaphones. The Thaksin government was forced to continually justify its legitimate mandate. But Thaksin must still have felt confident. Many had suggested that Thailand's heavily politicised armed forces had 'returned to the barracks' for good. We now know that such talk was premature.

W HEN the tanks and special forces units rolled out under a royalist haze on the evening of 19 September 2006, Thaksin was in faraway New York. There was no chance of a viable counter-attack. Now, for almost a decade, Thai politics has been caught in a seemingly limitless spiral of push-and-shove between Thaksin's supporters and those who backed the 2006 coup. This has never been a simple story, and there are many different gradations of allegiance, affection and affinity. Naturally enough some people have changed sides through these long and tumultuous years. But the basic deadlock remains and it has more to do with the Thai palace than the politics of Thaksin's democratic rise.

Since the May 2014 coup that brought General Prayuth Chan-ocha and his military machine to power, there have been few indications of a quick return to electoral protocols. For a start, Thaksin and his political allies remain too popular, and too smart. The juggernaut built in the early 2000s to contest elections has survived a thousand efforts to dismantle it. Even under military rule there are

When the tanks and

special forces units rolled

out under a royalist haze

on the evening of 19

September 2006, Thaksin

was in faraway New York.

There was no chance of

a viable counter-attack.

Now, for almost a decade,

Thai politics has been

caught in a seemingly

limitless spiral of push-

and-shove between

Thaksin's supporters and

those who backed the

2006 coup. clear signs, such as the persistence of underground red shirt politics and a rolling online anti-military campaign, that any loosening of draconian internal security procedures would lead to a quick resurgence of proThaksin politics. It is why the military regime's own constitution draft was rejected by the National Reform Council. Anxiety about Thaksin is still too strong.

The fundamental worry is about what happens when King Bhumibol Adulyadej is no longer on the throne. Everything else pales in comparison to this potential crisis. For almost 70 years, King Bhumibol has been at the centre of national life: an austere, fatherly, supreme figure, obscured by the pomp of one of the world's greatest royal houses. His standing among the Thai people has been carefully maintained by a vast and unrelenting public relations campaign. Almost every hour of every day the Thai people absorb messages about his contributions and the special status of his family.

The armed forces have also worked tirelessly to keep the king on the throne. Their penchant for military coups is legendary but perhaps what matters most is the unswerving fealty to the king shown by generations of senior generals. Whenever other military factions have sought to undermine royal standing they have been promptly stamped out. General Prem Tinsulanonda, the chairman of the king's privy council, has played this role going right back to the 1980s. He has now surrounded the king with retired officers who form a protective ring around a man who is ailing and whose fragile health could fade at any time.

$\mathbf{T}$ HE mortality of the king will come as a shock to many Thais, 95 per cent of whom were not alive 
the last time anybody else was on the throne. This gives the king an aura unmatched by other modern political figures and as his health wanes the mythology around his kingship only grows. He has only been seen in public on rare occasions in the past few years, always confined to a wheelchair. His public comments can no longer command the people's attention. In his final stage, the king is a distant and perhaps lonely figure, isolated at the top of what has become a precarious political order.

HIS is where the policy discussion gets tricky. So much of Thailand's future hinges on what happens when the king is no longer on the throne, but the conversation about such sensitive matters cannot happen in public. The use of the lèse-majesté law, Article 112 of the Criminal Code, and the Computer Crimes Act-another tool in the repressive armoury-mean that any hint of palace-related criticism can lead to a spell in prison. Thai authorities are unapologetic about how they handle these crimes. Some recent sentences stretch for decades and could potentially see the imprisoned die in jail. The threat of such punishments encourages most people to choose their words carefully. Yet others are prepared to take incredible risks to present alternative views on how Thailand should be run.

Whether royalist or republican, there is agreement on one thing: there is no obvious or unanimous path back to more representative or participatory government. Nor is there any indication that General Prayuth is tiring of his time as prime minister. Back in 2006 the military rulers-under the leadership of General Surayud Chulanont who was installed as unelected prime minister-took only 15 months from coup to election. The lesson has likely been drawn that this is insufficient time to do a full job of dismantling Thaksin's influence. The fact that Thaksin's sister, Yingluck Shinawatra, was prime minister from 2011 to 2014 only serves to reinforce the generals' sense of having to start all over again. De-Thaksinisation, this time around, will take more time.

The fact that Thailand's generals have received only mild criticism from the international community is also part of this story. In Southeast Asia there is almost no rebuke for countries that lurch back into military dictatorship. In fact soon after the 2014 coup General Prayuth greeted Myanmar's Senior General Min Aung Hlaing with a widely publicised hug. If there is one thing Myanmar and Thai generals have in common it is the ignominy of running military dictatorships. No doubt Myanmar's commander-inchief offered his sympathy.

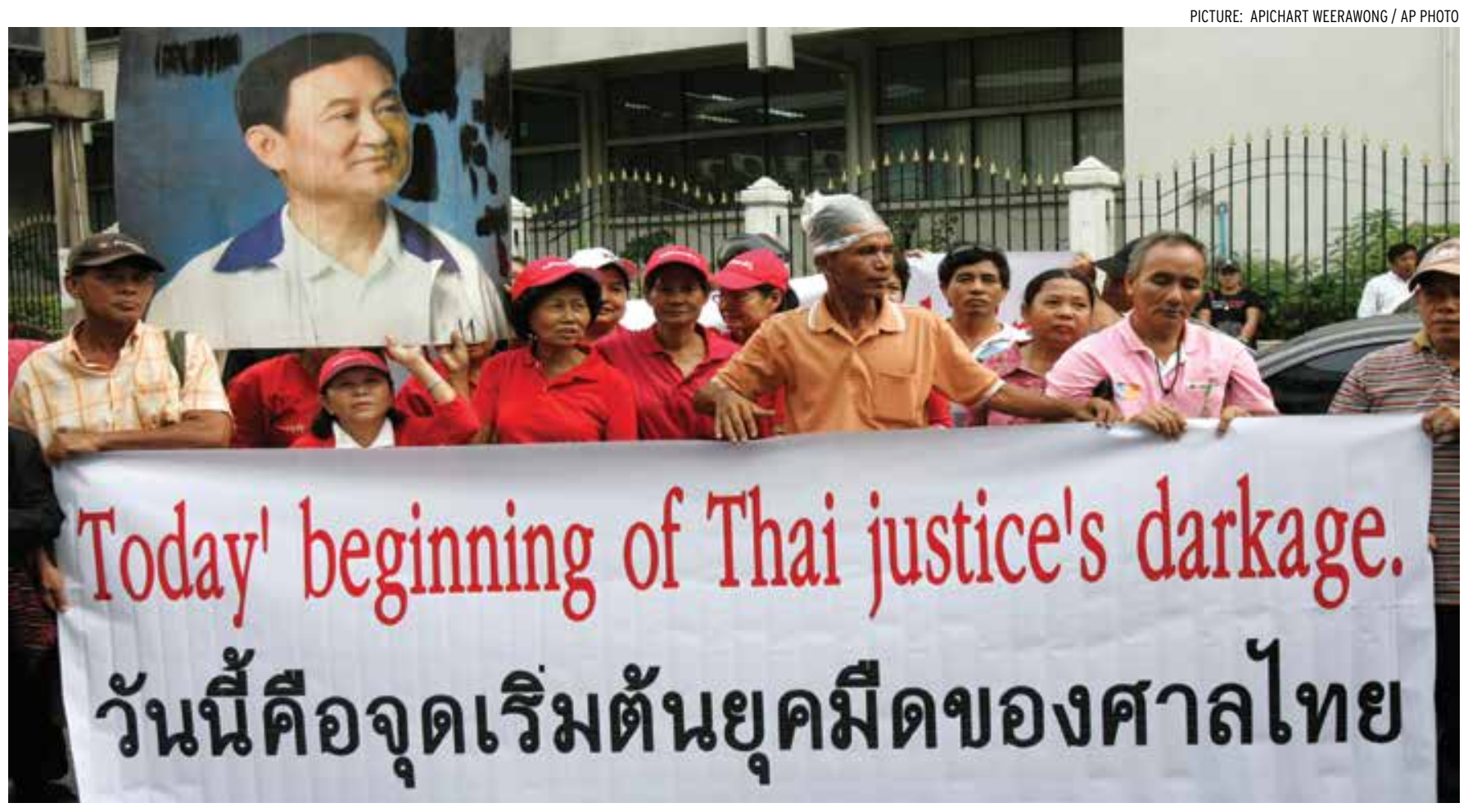

Supporters of ousted Prime Minister Thaksin Shinawatra hold a banner and his portrait during a protest outside the Supreme Court on 21 October 2008 in Bangkok. 
$\mathbf{E}$ LSEWHERE in ASEAN the tone tends to be pragmatic. It helps that Laos, Vietnam and Brunei are authoritarian systems of grand resilience. Of course, Cambodia, Singapore and Malaysia have also had their democratic ups-and-downs. Nowadays it is only the Philippines and Indonesia that set any regional standard for consistent democratic practice.

Further afield, it is inevitable that Thailand's supporters among the Western democracies make their statements with an eye to the future. While most are not prepared to give full endorsement to General Prayuth, they are aware of the broader picture. The United States and Australia, to take two examples, have maintained most of their security and other ties to the kingdom. They are fearful that Thailand will find support with China and leave behind its longstanding allies among the democratic West.

China goes to great lengths to ensure that the Thais are comfortable with its decisions and has planned major infrastructure investments to sweeten the deal. Thailand may prove an important part of China's southern push, with all the ambition of the so-called 'One Belt, One Road' likely to create extra capacity for Thailand to trade. China has no interest in pointing out flaws in Thailand's treatment of dissidents. They are, in that sense, increasingly likely to find common cause.

The ongoing investigation of the August 2015 Erawan Shrine bombing also gives China and Thailand another issue in common. Most of the dead were Thai and Chinese. Since the first hours after the attack there has been talk that the shrine was targeted because it is a popular destination for Chinese tourists.
Some have linked this speculation to Thailand's recent deportation to China of more than 100 Uyghur who were reportedly making their way to the Middle East.

With little solid information, and a haphazard investigation in progress, it is too early to know exactly what has occurred. Nonetheless, the possibility of an attack against Chinese interests on Thai soil has clearly got people's attention. In the days after the bombing, a Chinese government spokesperson warned that it was premature to suggest such a link, but as the investigation continues there is still a chance that the Uyghur issue is in play.

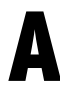
$\mathrm{T}$ THE same time, even the pragmatic Chinese leadership must be concerned that Thailand is perched precariously at the end of King Bhumibol's reign. They must be hoping that Thailand's elders and leaders may yet find a way to muddle through and create space for a new compromise between the different

Whether royalist or

republican, there is

agreement on one thing:

there is no obvious or

unanimous path back to

more representative or

participatory government.

Nor is there any indication

that General Prayuth is

tiring of his time as prime

minister. forces still looking for any chance to destroy their opponents.

It is precisely this winner-takes-all approach to statesmanship that has created the conditions for a decade's worth of grief. This can be measured not just in the blood spilled, careers destroyed and buildings burned, but in the immense loss of opportunity that the country has suffered. The rest of the world has not been standing still. Across Southeast Asia some countries have begun to take big strides towards closing gaps in development with their Thai neighbours.

7 HE most obvious example is Myanmar which has made moves towards normalising its internal and foreign affairs since 2011. This does not mean that Myanmar enjoys Thailand's economic or cultural heft, but there is certainly the potential for the country to make significant moves in that direction. Much will hinge on the performance of its government after the November 2015 election. As Thais well know, a democratic system takes decades to fully bed down.

So what will happen next for Thailand? Without its own robust institutions to manage legislative, judicial and executive power, the country once again looks to the palace for inspiration and guidance. The military knows that royal charisma helps to support their longer-term goals. Questions about authoritarianism can be quickly deflected as rebellious, anti-monarchy talk. As self-proclaimed custodians of the kingdom, the top generals imagine they are also protected by the king's benevolent aura. Such conflation of different powers-particularly when democratic concepts are belittled and electoral mandates destroyed-leaves the country without any immediate prospect of positive change. 


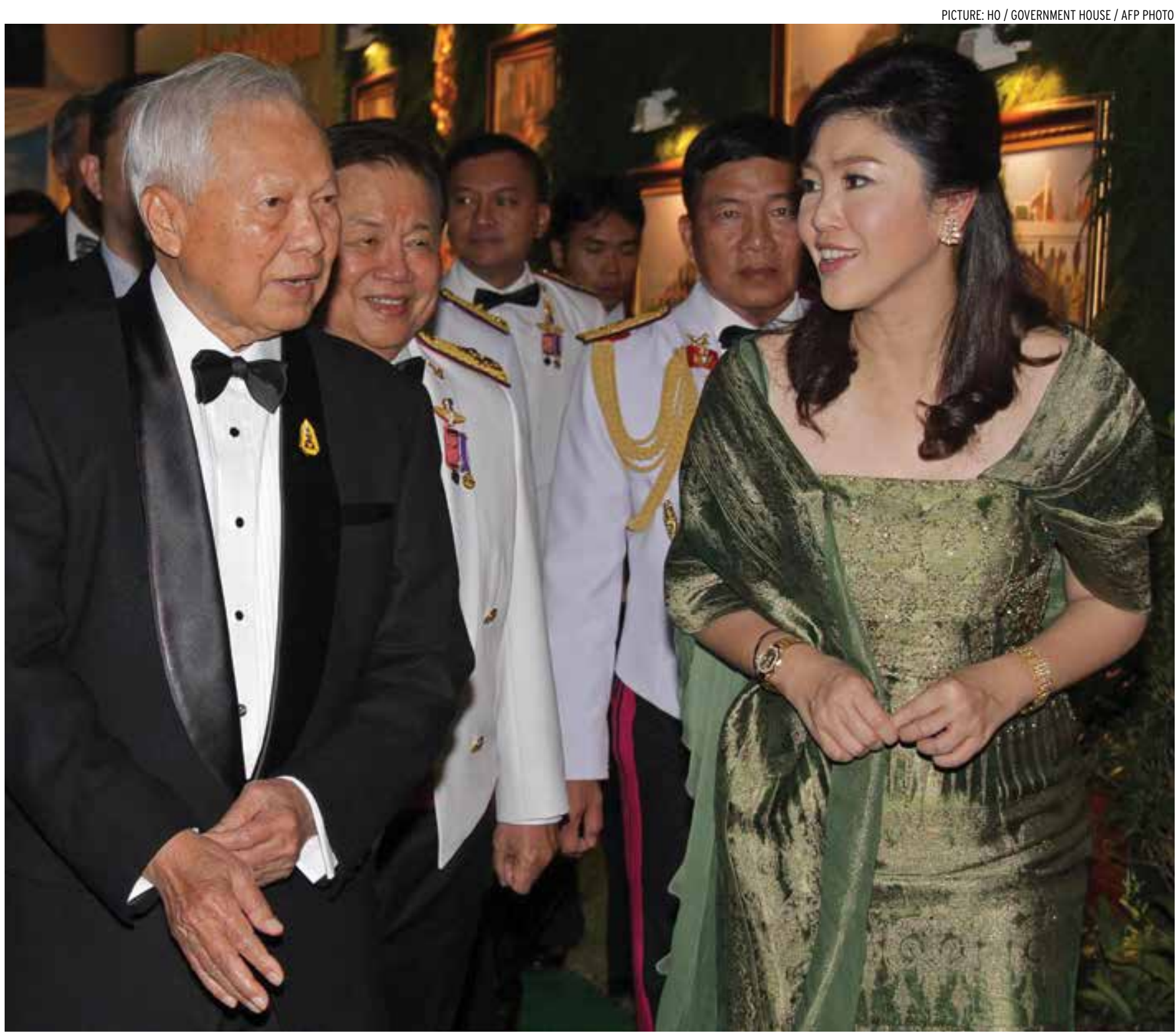

Then Prime Minister of Thailand Yingluck Shinawatra talks to General Prem Tinsulanonda, President of the Privy Council, during a gala dinner on the occasion of the Royal Thai Army Day on 19 January 2012.

NSTEAD General Prayuth and his

opponents are stuck, all waiting for the inevitable transition when King Bhumibol is no longer on the throne. Under such conditions many millions still also wait for Thaksin's return. They seem to respect his fighting spirit and the way that he has maintained a consistent political position for so many difficult years. Such people-the millions who voted for him in 2001, 2005, 2006 and 2011-do not tend to believe the charge that Thaksin seeks to overthrow the monarchy. Some even wonder whether he might not prove its greatest saviour, perhaps returning triumphant to support a future king or queen.

It is through such future repositioning of the Thai political elite that the big stories will be told. We tend to expect that we can understand alliances in ways that mean they will stay constant across time. But Thailand's topsy-turvy last decade suggests that there are too many different factors at work and that a violent showdown could be catalysed by the succession. Under these conditions the military will be forced to decide whether it ever wants to return power to the people. EAFQ

Dr Nicholas Farrelly is a fellow in the Bell School of Asia Pacific Affairs, The Australian National University. 


\section{China takes the lead in new climate change paradigm}

FRANK JOTZO

W HAT happens in China is central to the global effort to limit the extent of future climate change. China is already the largest emitter of greenhouse gases by far, even as it continues its process of urbanisation and economic modernisation. Under a traditional model of energy-intensive economic growth fed by fossil fuels, this would thwart the world's chances of keeping climate change at levels considered relatively safe. But a new paradigm of low-carbon economic growth could be the answer. Consistent with China's own national interests, this paradigm emphasises technology and is driven in large part by concerns other than climate change.

In the lead-up to the UN's 2015 climate change conference in Paris, China has taken a global leadership position on climate change policy, a fact difficult to imagine a decade ago. The long-held view was that acting on climate change is costly, and so it would fall on rich countries to do so, with developing countries to follow later.

That simple dichotomy holds no longer. The Paris treaty is shaping up as one with emissions pledges for all countries, whether developed or developing. But crucially, these targets are voluntary and a result of national decision-making processes, rather than legally binding and negotiated among nations, as was the case under the Kyoto protocol. Importantly, it provides a process to strengthen the ambition of national climate action over time.
Six years ago at Copenhagen, China submitted a relatively ambitious emissions pledge but seemed torn over the international status of its commitment and the role that China might play in the global climate policy framework. The pledge was accompanied by the traditional line advocating for a hard distinction between developed and developing countries. Since then, China has begun to accept the natural leadership role that falls to it, not only because of its size, rising income and geopolitical status but also because taking the lead offers substantial benefits. And that leadership role is up for grabs, given European economic woes and the limits American politics puts on the US administration's ability to take bold action.

HINA'S submission to the
Paris negotiations still uses the traditional language of 'differentiated responsibilities and capabilities' and urges developed countries to do more on climate change. But it also says that China will 'take on international commitments that match its national circumstances' and 'will promote global green low-carbon transformation and development path innovation.

Those last few words are the key. China has realised that it has a strong self-interest in addressing climate change. For one, the economy is now large enough that China's own actions will strongly determine the extent of adverse effects from climate change on its own economy and society, while also significantly influencing how the rest of the world acts on the issue.
D UT more importantly for the near term, cutting carbon emissions goes hand in hand with China's other national objectives. One is to clean up the air pollution that plagues many Chinese cities and shortens people's lives. In the short term, this can be improved by cutting back coal use, especially in inefficient plants close to cities, while in the medium term, a shift to electric vehicles and improvements in public transport and city planning is needed. Both efforts are underway in many of China's cities. Another objective is to improve China's energy security, principally by cutting back on the reliance on importing fossil fuels.

International agencies, including the World Bank and OECD, as well as national governments increasingly view low-carbon development as a way to achieve better overall development outcomes. While investing in new technology to reduce carbon emissions has traditionally been seen as an economic cost, it is now often regarded as an opportunity for economic modernisation and growth.

China is in a position to set the trend for many other countries that are following in its footsteps. It could become the dominant provider of many of the new technologies that will characterise the global energy and industrial system if the world is serious about the climate change challenge. China is already the world's largest producer of solar cells and wind turbines, and it could aspire to global leadership in areas such as 


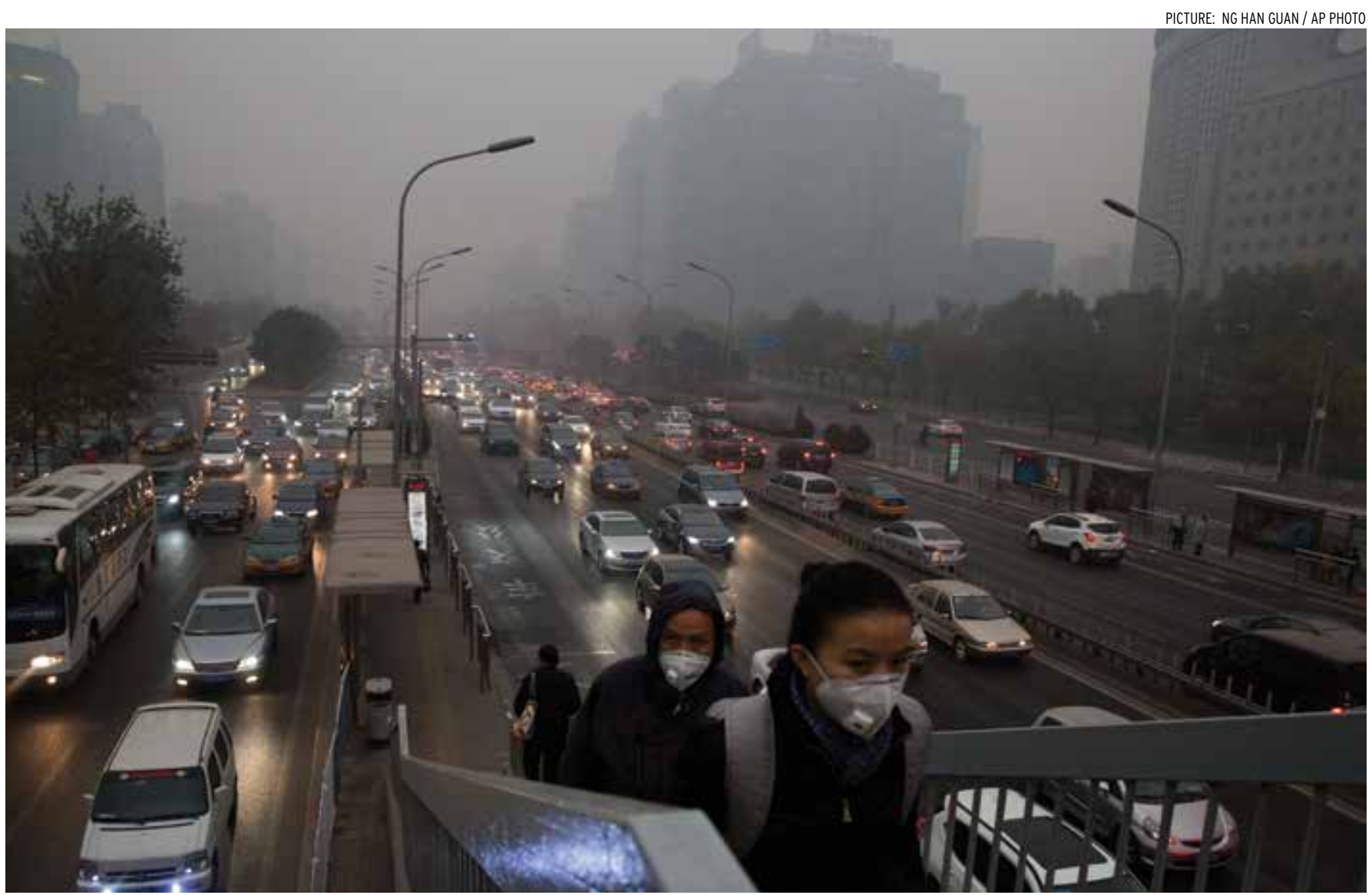

Pedestrians wear gas-masks against the pollution as they cross an overhead bridge in Beijing, China, in 2014. China has paid a high ecological price for its rapid GDP growth in recent decades. Can it use its new wealth to restore its environment?

electric vehicles and new transport systems, nuclear power plants, advanced electric grid technologies and 'smart' buildings with minimal energy footprint.

China's headline climate goal is expressed as a reduction in the emissions intensity of its economy, or the ratio of carbon dioxide emissions to GDP. The existing goal has been a 40 to 45 per cent cut in emissions intensity between 2005 and 2020 . The new goal, added on top of the 2020 pledge, is a reduction in emissions intensity of 60 to 65 per cent from 2005 to 2030. This amounts to an annual reduction of around 4 per cent, year after year over a quarter of a century.

There are few historical examples of such decarbonisation rates being achieved over prolonged periods of time, the main instances being in the transformation of formerly socialist economies of Eastern and Central Europe, and China during the 1980s in the first wave of economic reforms. None of them lasted for as long as China's pledge implies. Yet the target is realistic because of the huge potential for energy efficiency and for moving away from coal, which still dominates China's energy supply.

C HINA is on track to meet and perhaps outperform its 2020 target. The key factor to success has been improving energy efficiency throughout the economy, with inefficient old industrial and energy sector equipment being scrapped in favour of newer, more efficient plants.

There is still scope for further technical improvement in many parts of the economy. But to meet the 2030 target, China will also need to see a structural shift in its economy towards services and high-value added manufacturing, as well as a shift in the composition of its energy supply away from coal and towards carbon-free alternatives.

China has also pledged to reach its peak carbon dioxide emissions level by around 2030 and to make efforts towards this happening earlier. What year 'peak $\mathrm{CO}_{2}$ ' will occur under the announced emissions intensity target essentially depends on future GDP growth rates. As long as annual GDP growth is above the annual decarbonisation rate, emissions will keep growing; as soon as the rates equalise, peak $\mathrm{CO}_{2}$ is reached. China's economic growth is now moderating and with 
the prospect for much slower growth down the track, it is quite possible for emissions to peak before 2030. It might occur much earlier if structural change and investment in low-carbon options proceed rapidly.

Indeed, some observers expect that emissions may peak by or around 2020. It is likely that China's coal use is already near its peak, or might have peaked already. China's overall carbon emissions are still rising on account of increases in oil and gas consumption, but these are much less carbon intensive than coal, per unit of energy. Steel production is already declining as the infrastructure investment boom subsides. In any case, China's period of steeply rising emissions is already over, and it is quite possible that the emissions trajectory will level out and remain at a relatively stable level for some time to come. If emissions flatline, the precise year of the peak is not of particular importance.

A CCELERATED structural change and a shift to low-carbon energy sources are in line with Chinese economic policy objectives. China's submission to the Paris conference mentions as a goal the promotion and development of service industries and 'strategic emerging industries', as well as 'strictly controlling the total expansion of industries with extensive energy consumption and emissions'. It also targets a sharp increase in non-fossil fuel energy sources, to around 20 per cent of the total energy mix by 2030 , through continued rapid expansion of hydropower, solar, wind and nuclear power.

Renewable energy is no longer an expensive luxury: the cost of electricity from solar panels, for example, has fallen from sky high to being almost competitive with new coal fired generating capacity. This is thanks to a continued global research and

development effort and a massive expansion of production capacity, first through mainly European subsidy schemes and then with China's takeover of mass production of solar cells. The costs of new technologies keep falling, while old technologies remain stagnant.

\section{OW-EMISSIONS electricity \\ capacity is growing rapidly.}

Nevertheless, the policy effort to get to a point where these alternative power sources provide a large share of total energy in China will be enormous, because solar and wind power are coming off a very low base in China and the system overall is still geared towards large, centralised plants.

Command-and-control approaches have dominated China's energy and climate policy toolbox, including through mandated closures of highly polluting plants, energy efficiency regulations and state-directed investment in renewable power. But market-based policy instruments are to play a much bigger role in the future. In line with a general drive to liberalise the economy, China is preparing a national emissions trading

What plays out in China

will reverberate across

Asia and the world.

Governments and

businesses will feel the

effects of China's

low-carbon push. scheme, foreshadowed for introduction in 2017. The cap-and-trade scheme is to cover electricity generation and heavy industries such as iron and steel, chemicals, building materials, papermaking and nonferrous metals.

It is expected that China's provinces will play an important role in the administration of such a scheme, with pilot schemes in operation for several years now in five of China's cities and the two provinces of Guangdong and Hubei. Their effect has been limited, but that is unsurprising as their real purpose has been to test the concept, and in that they are succeeding.

For emissions trading in China to become fully effective, it will need significant changes, including market reform. Large parts of heavy industry and the electricity system are still run by state regulation or as state-owned enterprises. Making emissions trading effective will require significant energy sector reform, in particular giving a much greater role to pricing mechanisms than is presently the case, especially in the electricity sector.

UCH reform can be hard to do as it cuts across established financial interests, but at the same time the introduction of emissions trading could be a catalyst to push ahead with faster market reform in China's heavy and energy industries. The efficiency benefits from such market reform are by themselves a significant prize-yet another instance of more traditional policy objectives hand in hand with the low carbon objective.

China's move towards effective emissions markets will be a gradual one. But it can have a big signalling effect. The world's largest economy putting a price on carbon emissions will be noted the world over and emulated if successful. And Chinese policymakers will likely get some quiet 


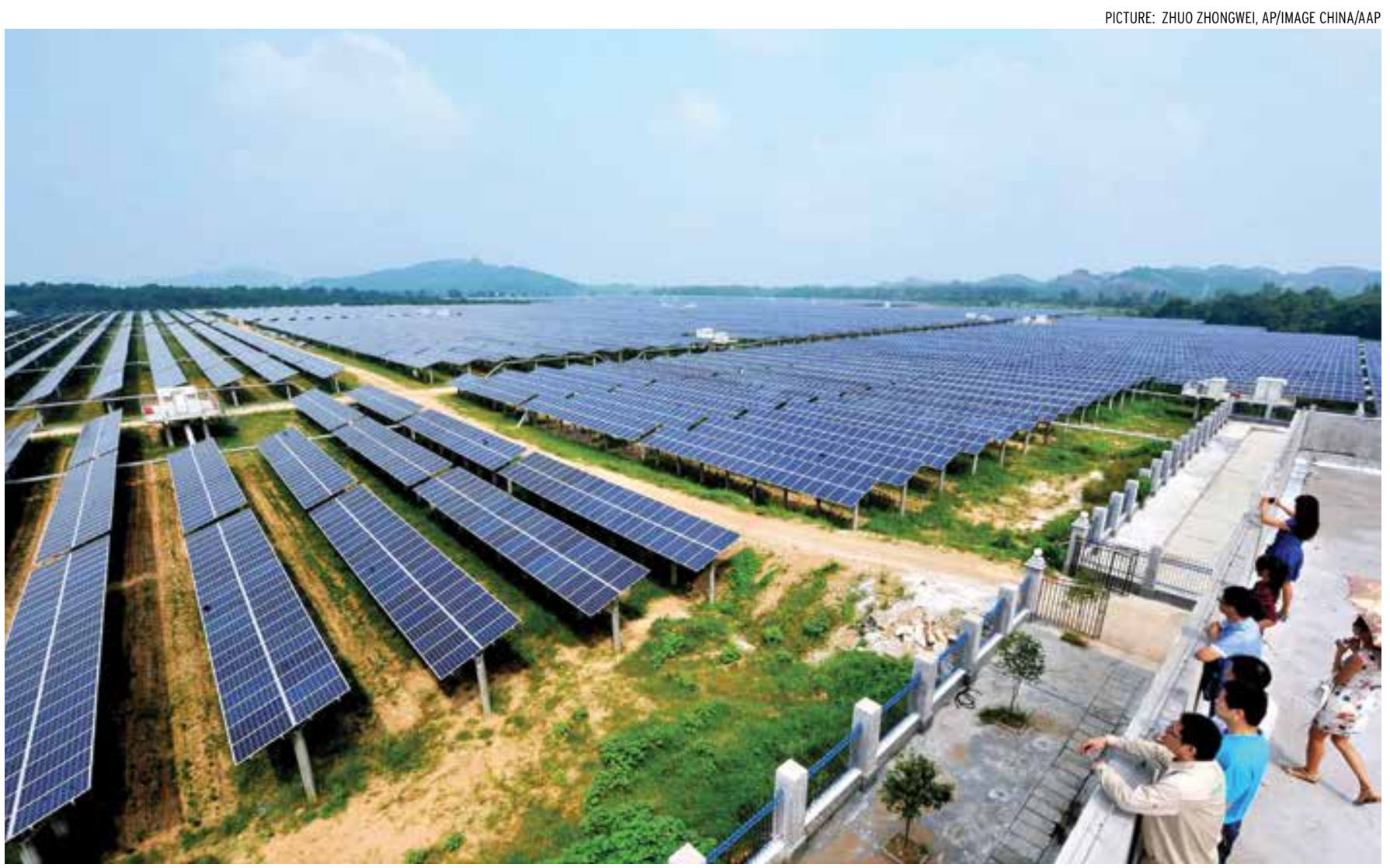

A photovoltaic power station in Heng Feng county of China's Jiangxi province in August 2015. The cost of solar power has fallen dramatically in China to be almost price-competitive with coal thanks to rapid technological advances.

satisfaction from the fact that they are implementing cap-and-trade, a quintessentially capitalist instrument of regulation and one invented in America, while it is politically impossible to have a national scheme in the United States.

W HAT plays out in China will reverberate across Asia and the world. Governments and businesses will feel the effects of China's lowcarbon push. It is high time for countries that have strong trade and investment relationships with China to engage deeply on the new economic and strategic trends that come from China's climate policy. Australia, for example, will see a continued decline in demand for coal and iron ore, but it should pursue the opportunities in supplying China with the raw materials and know-how it needs for its low- carbon push, and be ready for greater Chinese demand for Australian services and agricultural products.

Developing countries have a choice as to whether their economies grow in the traditional way. This includes whether they rely more on renewable power than on coal, rail rather than roads, and highly integrated cities rather than sprawling suburbs. These cleaner options are not only good for the climate but also better for the local environment, health and productivity.

Technological and economic push factors are at work. Cheap Chinesemade solar panels have created a fast growing market for renewable energy the world over, including in low-income developing countries. The same can happen with other new energy technologies. China is in a good position to influence global product market trajectories and steer financing for infrastructure investments in other countries.

7 HE pull factors are not to be underestimated. If China's shift to a greener shade of economic growth works out, then other emerging economies will try to emulate it. If China succeeds in cutting short the dirty phase of industrialisation through technology and accelerated structural change, then why would any country be content with second best technology and an outdated model of development? EAFQ

Frank Jotzo is an associate professor and director of the Centre for Climate Economics and Policy at the Crawford School of Public Policy, The ANU. 


\section{Eco-solutions for a sustainable Asia}

YONGSHENG ZHANG

A CCOUNTING for about 60 per cent of the world's population, Asia is a very big family that varies greatly across and within its regions. From Northeast and Southeast Asia to Central Asia, South Asia and the Middle East a plethora of ethnic groups, cultures, environments, economic models, historical ties and government systems all bump up against one another. One thing Asia's constituents have in common is the challenge posed by the transition to green growth. Nonetheless, that challenge also presents enormous and varied opportunities. And just as there's no universal green growth model, opportunities will also differ from country to country.

Since the industrial revolution and the start of so-called modern economic growth, global material wealth has been dramatically expanded. Though the development paradigm has brought prosperity, especially for those in industrialised countries, it has caused severe environmental consequences, including climate change, pollution, biodiversity loss and more. The breakdown in boundaries between man and nature is giving rise to inevitable crises.

The existing development paradigm is not just environmentally unsustainable and infeasible but also appears removed from the ultimate purpose of development-happiness. Studies by economists, psychologists and sociologists show that the happiness level of people increases with level of GDP per capita but only slightly. For instance, Singapore has a much higher GDP per capita than that of India, but the happiness scores of both countries are exactly the same, and both are significantly higher than that of Japan. Since 1958, Japan's GDP increased more than five times in real terms. But its average happiness measure didn't show an upward trend. Similar observations can be made elsewhere.

$\mathbf{U}$ NFORTUNATELY, the development path of industrial countries-and the lifestyle that goes with it-is treated by most developing countries, including those in Asia, as not only a target but also the law of economic development they must follow. But Asia needs to fundamentally rethink whether such a development paradigm should be the target of their modernisation. As the world faces global environmental crises, it's no longer a matter of whether to take up green development but how. Not only are emerging economies no longer able to achieve the established pathway towards economic development, but developed countries are also required to accelerate the shift towards green economies.

Despite their dynamism, most Asian economies are still in the process of modernisation and, for many, poverty reduction remains a significant challenge. If the traditional industrialisation path is no longer feasible, then the question arises: can the Asian economies, especially the poor economies, achieve prosperity through green growth? The answer is yes, but it really depends on whether they understand what green growth is all about and how to seize its opportunities.

Identifying opportunities requires understanding the idea of green growth. This is not just an issue of energy preservation, emission reductions and renewable energy but a comprehensive and profound transformation of the development paradigm.

A new theory is needed. As Albert Einstein pointed out,'[i]t is the theory which decides what we can observe'. If we think only within the conventional analytical framework, then we will be limited by our preconceived notions that carbon mitigation and environment preservation are a burden to growth, and we will be unable to see that they are opportunities. Unfortunately, mainstream economics has limited capability to predict the green growth opportunities that will emerge from the structural changes of a green economy.

17 E NEED to think outside the box. Just as the people alive in the agricultural era could never imagine the business opportunities of the industrial era, today's industrial society cannot see the opportunities afforded by green growth. This is especially so in the context of the digital age, which constitutes a fundamentally different growth paradigm with never before seen business opportunities.

There is a chicken-and-theegg dilemma that needs to be 


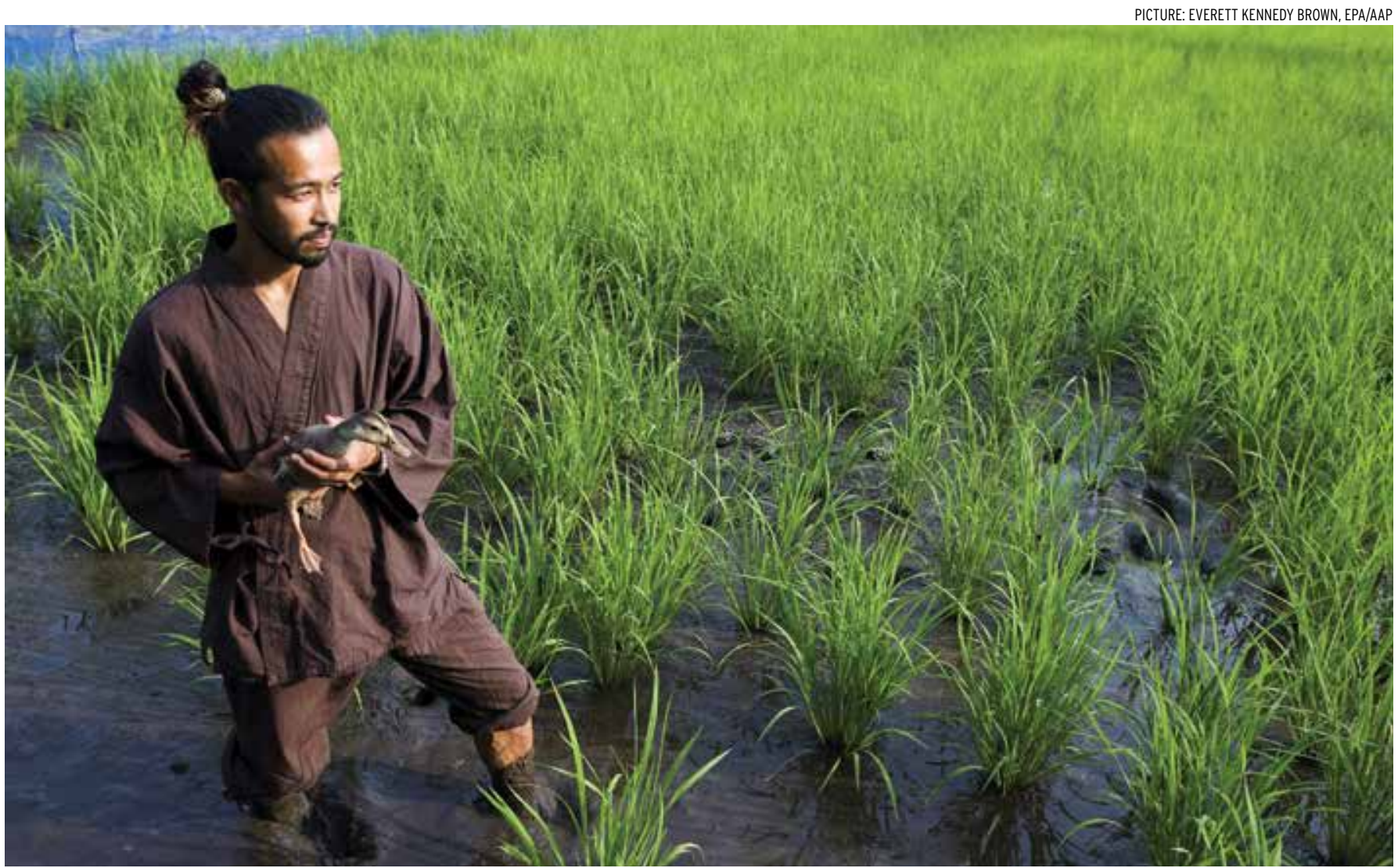

Japanese farmer Tepei Suzuki holds a duck in his organic heirloom rice field in the town of Isumi, east of Tokyo in Japan. Suzuki uses ducks in his fields for weed and pest control. Rice-duck farming is a prominent example of effective eco-friendly farming practices.

broken. Some people argue that the government should not take strong action to promote green growth since there is not yet sufficient evidence of its benefits. But if no action is taken, there will be no evidence. Green growth is a self-fulfilling process; once triggered, it will gain momentum.

\section{REEN growth should be \\ 5 understood in the context of} the digital era. Currently, human society is in transition from the industrial era to the internet era. This transition is dramatically impacting the traditional development paradigm. Many concepts-from resources to urbanisation, from production and consumption to business models-are undergoing unprecedented change. This change makes it possible for the poor regions to leapfrog the traditional development pathway to a new economic pattern.

There are two complementary, but also very different, ways of thinking about achieving and exploring the opportunities of green growth. The first takes the existing consumption pattern in industrial societies as given, and assumes that green growth aims to achieve the same consumption but in a greener way. The second not only considers greener production, but more importantly, the consumption of green products and services. The latter represents a paradigm shift.

Unfortunately, almost all developing Asian countries seek to emulate the consumption patterns of the advanced economies. Consequently, they not only pursue the advanced countries' high carbon growth paths, but also duplicate their consumerism and materialism leading to the existing environmental crises. This may be a wrong approach for their economic modernisation.

ANY people tend to think $M$ that green growth is expensive and highly dependent on future technological breakthroughs. This is not the case. The major challenges of green growth are not from the unavailability of cost-effective technologies or alternative solutions, but because of the lock-in effect as well as policy and institutional barriers that make the application of technology and alternative solutions difficult.

Once an economy is locked in a particular pathway or structure, its transition cost to a new one is high due to vested interests and high sunk costs.

Burning of fossil fuels is the major source of global carbon emissions and climate change. While renewable 
energy is an alternative, it is often argued that the renewable energy sector is too costly and cannot survive without relying on government subsidies. This is somewhat misleading. What is most needed for fostering renewable energy is not government subsidies but a level playing field on which to compete with the fossil fuel sector.

F YOU take the two types of

subsidies given to fossil fuels into account, renewable energies are actually much more cost-effective. The first are direct subsidies. Total annual global subsidies to fossil fuels, according to the International Energy Agency, are estimated at around US $\$ 550$ billion. The second is the external cost of fossil fuelstheir externalities. According to a working paper of the IMF, if things like the health costs of air pollution are included, the subsidy afforded to fossil fuels reached US $\$ 5.3$ trillion in 2015 , which is equivalent to 6.5 per cent of the global GDP.

But efforts to reduce our ecological footprint are not limited to nationwide energy production. Take the agriculture sector, for example. Rice production in Asia accounts for about 90 per cent of global rice output. Yet it is highly dependent on chemical fertilisers, pesticides and herbicides, and has severe environmental impacts on water, soil, air and biodiversity. The integrated riceduck farming (IRDF) system is one of a variety of eco-solutions. It was created by Japanese organic farmer Takao Furuno in 1989 based on the traditional practice in Asia.

The idea is simple: when ducks are placed in a rice paddy, the rice and ducks become perfectly symbiotic. Ducks eat harmful insects and weeds, meaning there's no need for chemical pesticides and manual weeding in the rice field. Ducks produce droppings that act as a natural fertiliser, while their continuous movement provides natural stimulation and aeration, which increases the availability of nutrients like nitrogen, phosphorous and potash to the rice crop. Methane gas emissions from IRDF rice fields have also been shown to be around 30 per cent lower.

Though this farming method is applied in some areas of China, Japan, South Korea, the Philippines and Bangladesh, its use is not as widespread as is deserved. A major reason is that to realise its high market value, the organic IRDF needs

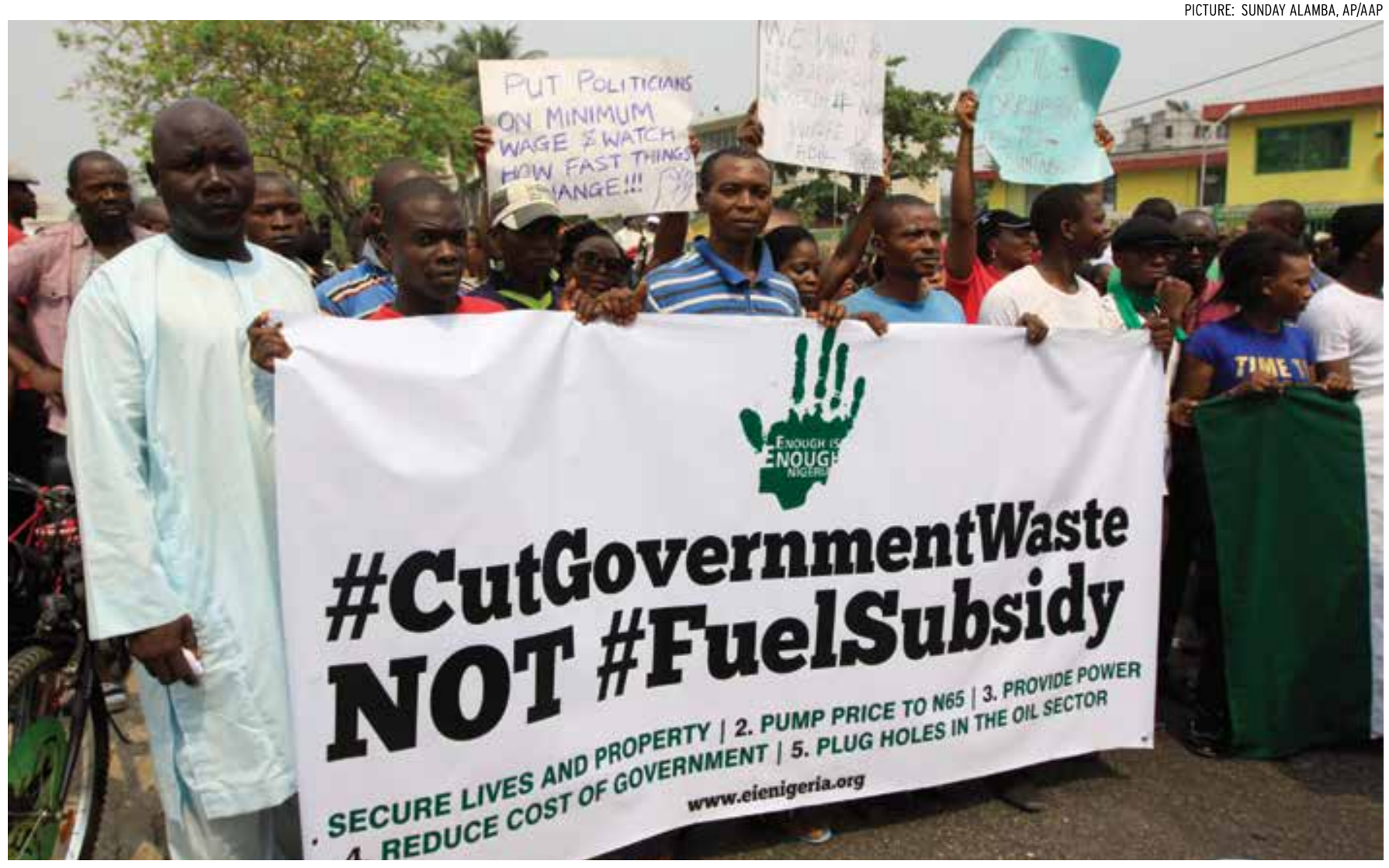

Angry youths protest the removal of the fuel subsidy in Lagos, Nigeria, 12 January 2012. Fuel subsidies disproportionately benefit the rich and are distorting consumption and research away from cleaner alternatives, yet remain a populist issue in many countries. 
different marketing, distribution and business strategies so as to distinguish its products from the conventional rice produced in chemical-based agriculture. This is a challenge to all existing small spotbased farming systems. Equally, the chemical and pesticide industries that have benefited from governmental subsidies have also become vested interest groups, and a barrier to the scaling-up of eco-agriculture.

M ORE fundamentally, it is important to recognise agriculture is being industrialised according to the logic of manufacturing worldwide: socalled 'industrial agriculture'. Yet the nature of agriculture, as an integrated part of a whole ecosystem, is substantially different from the nature of manufacturing. As long as agriculture is pushed in the direction of industrial agriculture by industrial capital, sustainable agriculture could not be achieved.

Household energy consumption, including heating and cooling, accounts for about 30 per cent of total energy consumption in China. Here passive houses are an alternative to conventional structures. These require very little energy for heating and cooling, which greatly reduces a household's energy consumption and its ecological footprint.

S INCE 2009, China's Ministry of Housing and Urban-Rural Development and the German Energy Agency have together been exploring the use of passive houses and low energy buildings in China. Energy Foundation China, which aims to promote the transition to sustainable energy, funded a pilot project of passive houses in Qinhuangdao city, Hebei province. The success of the project demonstrated that the construction of passive housing in China is technically feasible, environmentally friendly, healthy and cost-effective. Huge energy savings can be achieved without compromising comfort.

The above examples demonstrate the various ways we can use cheap green solutions to more-sustainably enjoy the consumption levels of industrial economies. Furthermore, there is huge potential for green growth in the less developed areas of Asia. And if emerging economies don't simply follow the consumption and lifestyle patterns existing in the industrial societies, there are further opportunities for more sustainable growth. Economic growth should meet all human needs, not just the physiological needs that have been prioritised in traditional industrialisation. Other human needs-such as safety, belongingness and love, esteem, and self-actualisation, transcendencecan also be important sources of economic growth, and give rise to various new products and services. For instance, Facebook and WeChat are among the most dynamic emerging services to meet the needs related to 'belongingness and love', but these kinds of non-physiological services were not widely seen as value-creating and source of growth in the past.

This is particularly germane to the development of poor regions that have not been locked-in to non-green economic structures yet. In traditional growth models, rural areas are seen as places that merely provide agricultural products and surplus labour for industrialisation and urbanisation. The non-material green resources of these areas-such as ecological resources, leisure, culture, heritage and the aesthetics of the landscape-are largely ignored.

For this reason, the research team of 'Climate Change and Green Growth' at the Development Research Centre of the State Council in China (DRC) is conducting some green growth pilots and demonstrations in some poor regions in China to show how green growth could accelerate their development. For instance, in an agricultural county in Hubei Province of middle China, professional institutes are helping the local people to protect their ecological environment and there by enhance the market value of their agricultural products. The associated transformation of conventional industrial agriculture, which is highly reliant on chemical fertilisers, pesticides, herbicides, antibiotics and hormones, into eco-agriculture provides high quality ecological base material for relevant manufacturing and services. Various eco-solutions have also been introduced, including passive houses and constructed wetlands for waste water disposal, to improve the quality of living in the countryside. This will in turn be a catalyst for various services in the countryside, such as eco-tourism.

$\mathbf{U}$ LTIMATELY, a mutuallyreinforcing balance between the environment, economy, society and culture could be established by exploring new green growth pathways. Given Asia's diversity, various green growth models could be explored according to the characteristics of different regions. EAlP

Yongsheng Zhang is a senior fellow and Chief Expert on Climate Change and Green Growth at the Development Research Centre of the State Council, China. 


\section{How to go green without its being a struggle}

\section{ZHONGXIANG ZHANG}

$\mathbf{T}$ HE effects of the rapid growth of the world's second largest economy are visible everywhere. China's pollution is raising environmental and health concerns, and steeply rising oil imports raise questions around energy security. Chinese leaders are deeply aware of the challenges and have placed ecological goals at the same level of priority as economic, political, cultural and social policies.

Burning coal contributes to the overwhelming majority of national sulphur dioxide, nitrogen oxide and carbon emissions in China. The country produces and consumes about twice as much coal as the United States. Dominating the electricity sector, coal has accounted for over two-thirds of China's primary energy consumption for several decades. Current installed capacity of coalfired power plants is more than that of the United States, Britain and India combined.

This has given rise to unprecedented environmental pollution and health risks across the country. Given China's coal-dominated energy mix, cutting carbon intensity to meet 2020 climate commitments means cutting energy intensity. When peak coal occurs will be crucial to determining peak carbon emissions.

Proposals to cap total national energy consumption have been slow to get off the ground. The dense smog that frequents Chinese cities-the combined effect of heavy airborne pollution and meteorological conditions-has sparked determination to cap coal consumption and combat air pollution. While the growth in coal production appears to be slowing, the key challenge for China is to let coal consumption peak in 2016-20 to allow carbon emissions to peak in 2025-30.

Industry accounts for about 70 per cent of China's total primary energy consumption. The Chinese government has made huge efforts to change the current energy-inefficient and environmentally-unfriendly pattern of industrial growth. But the country needs to enhance industrial policies to encourage technical progress, strengthen pollution control and promote industrial upgrading and energy conservation much more. With a few key energyconsuming sectors, a sectoral approach is seen as the first step. The cement, steel and aluminium sectors have been identified as priorities.

C HINA could cap its absolute greenhouse gas emissions by around 2030. The International Panel on Climate Change recommends that global greenhouse gas emissions should peak by 2020 to avoid dangerous climate change consequences. But given China's relatively low stage of development and its coal-fuelled economy, its carbon emissions are projected to grow beyond 2030, despite energy saving policies. Even if it maintains its Copenhagen pledge, achieving a carbon intensity reduction rate of approximately 3 per cent annually from 2016 to 2050, its carbon emissions would not peak until 2040. With extra effort, and given previous grace periods on international treaties, 2030 is a reasonable goal. Any longer would be unreasonable for a country of China's immense size.

D EAK carbon in 2030 means that China would need to bring its current target forward at least a decade. While this commitment is ambitious, it would not be enough to avoid a global surface temperature rise of two degrees by the end of 2100 , which is widely considered as a requirement of avoiding dangerous climate change. This would require a peak in 2020-25. China's emissions must decrease very quickly for the target to be achieved. So even if China were to peak in 2030, the necessary emissions reductions afterward are unlikely to be achieved.

Capping China's carbon emissions around 2030 would cost 0.02 per cent and 0.06 per cent of China's GDP in 2020 and 2030, respectively, without considering other benefits of carbon abatement. The EU commitments are widely considered less stringent, partly because its 30 per cent reduction compared to 1990 would cost $0.2-0.3$ per cent of GDP in 2020. While China may not be expected to better Europe, the small loss projected could leave room for China to peak earlier.

This could be achievable. With Chinese cities responsible for more than 60 per cent of total energy consumption, China began 


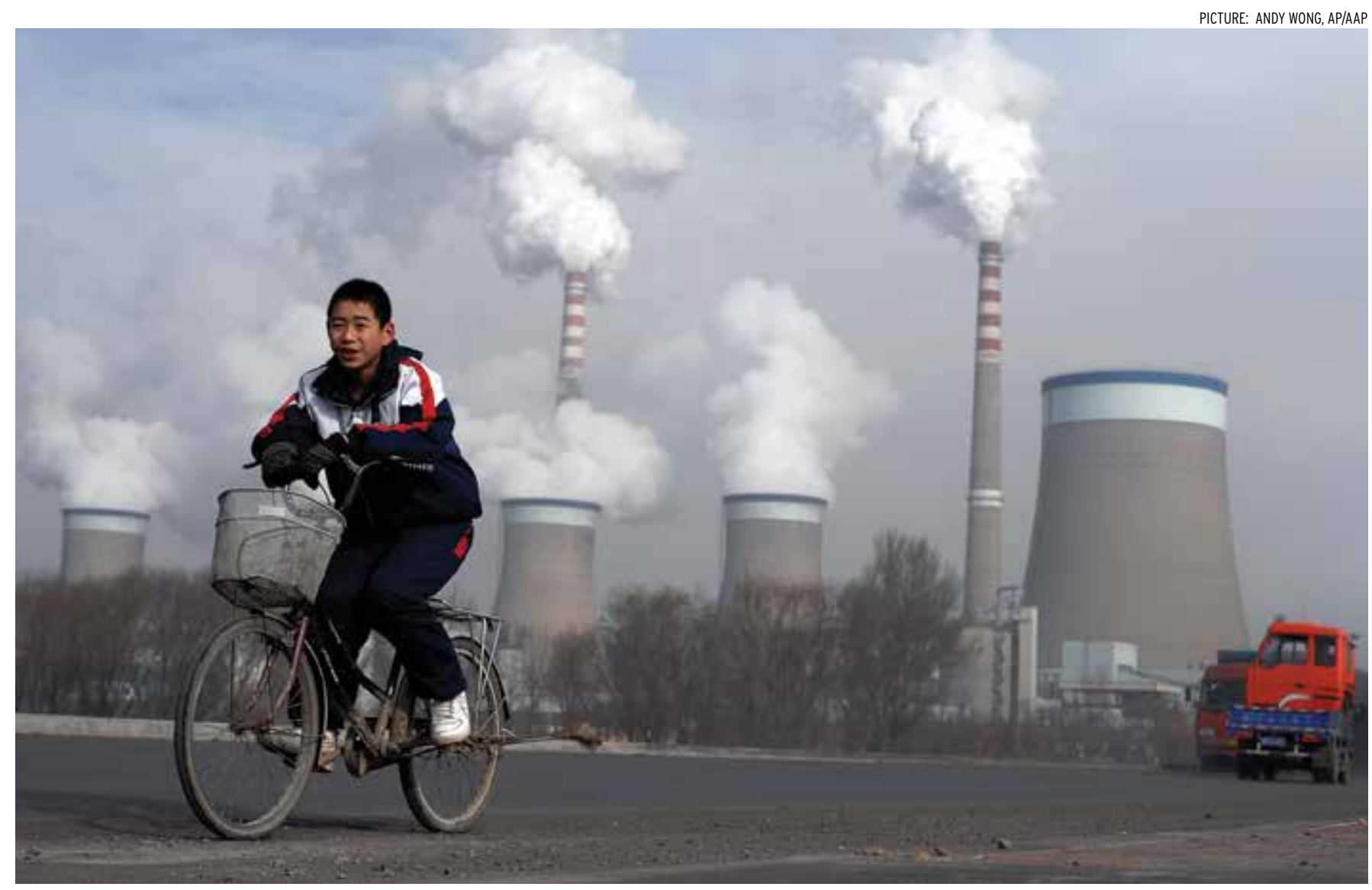

A Chinese boy cycles past the cooling towers of a coal-fired power plant in Dadong, Shanxi Province, in 2009. Coal has been the principle fuel of China's spectacular economic growth in recent decades but will need to be toned down if China is to curb its emissions intensity.

to experiment with low-carbon city development in 2010. All the pilot provinces and cities set carbon emissions peaks in 2030 or earlier-even 2015 in Ningbo. More experimentation is planned. The practice and ambition of the pilot regions sets a good example for abating emissions and could allow China to peak earlier.

$\mathbf{T}$ HE level at which China's emissions will peak remains unknown. Estimates of China's peak emissions differ significantly across studies, but are unlikely to be lower than 10 gigatonnes in 2030 .

China has implemented a variety of programs and initiatives to reduce carbon emissions, including mandatory closures of small, inefficient power plants. Supportive economic policies are also being implemented to encourage technical progress and strengthen pollution control. These initiatives will need to be strengthened and expanded.

Renewable energy is another long-term solution and has been identified as one of seven strategic emerging industries. China has targeted alternative energy sources to meet 15 and 20 per cent of its energy requirements by 2020 and 2030, respectively.

But China needs to complement administrative measures with market-based approaches. Administrative measures can be effective but are not efficient. Harnessing market forces to reduce energy consumption and cut carbon will be crucial to success.
Getting energy prices right is the first step in sending clear signals to both producers and consumers. China has moved away from centrally planned pricing towards a more market-oriented pricing mechanism, though the pace and scale differs across energy types. Electricity has lagged far behind, with the government still retaining control over electricity tariffs. The natural gas price has also long been set below production costs. This complicates pilot carbon trading schemes in China's power sectors. Thus power pricing reforms are critical for internalising the cost of carbon in energy market prices.

C HINA ran pilot carbon trading schemes during 2013-15. Unlike the EU system, the pilots cover 
both electricity generated within the pilot region and imported from outside. Pilot regions were given leeway in how to design the schemes, including which industries would be affected, how much they would cut, who would be allocated permits and where the energy would be sourced. Hence, effects varied significantly across regions. But they have been generally successful, giving China impetus to introduce a national carbon market.

Until a fully-fledged national ETS is established, China's regional schemes will be expanded and continue to function in parallel. In the national scheme, the threshold for an emissions source to be covered will be set at 26,000 tons of carbon dioxide equivalent annually. This means the market will involve an estimated 2-3 billion tons of carbon dioxide emissions a year, making it the world's largest scheme. This nationwide carbon market will become fully functional after 2019 .

\section{HINA'S green push is not completely new. Former leaders} $\mathrm{Hu}$ Jintao and Wen Jiabao recognised the seriousness of environmental degradation in China and insisted that encouraging economic growth at the expense of the environment had to end. But there is now an imperitive to push efforts further to meet global goals. It is in China's interest not only to sustain its economic growth but also to ensure its standing in the world. If Xi Jinping and Li Keqiang can make China 'green', history will indeed record their contribution as equal to that of Mao Zedong and Deng Xiaoping. EAFO

\section{ZhongXiang Zhang is a distinguished university professor at the College of Management and Economics, Tianjin University, China.}

INTERGENERATIONAL WELLBEING

\section{Wealth accounting is critical for measuring sustainability}

KEVIN J. MUMFORD

$\mathbf{S}_{\mathrm{e}}^{\mathrm{U}}$ UPPOSE you are an investor evaluating a company, but you only have its income statement. There you have revenue, expenses, profit and profit growth. If the company has experienced high profit growth then this may indicate future growth, and imply a sound investment. But if you can't tell whether the company is simply selling off its assets, as shown on the balance sheet, then you will not have a good idea of the company's potential for future growth. This same logic applies for measuring the wellbeing and development of nations and communities.

Just like profit on an income statement, GDP is useful, but has its limitations. For measuring wellbeing, these limitations arise because GDP only measures current economic activity and not the potential for future growth. Just like a company's balance sheet, national wealth accounting provides a measure of a country's potential for future economic growth. This is a strong analytic basis from which to judge intergenerational equity and the sustainability of development.

When economists study development, the focus is usually on income. The most common measure of income for an entire country is
GDP, a measure of the value of all market goods and services produced in the county in a year.

This focus on goods and services when trying to measure development may seem restrictive. What about family, friendships, safety, meaningful work, recreation and other factors that determine human happiness? These are important outcomes of genuine progress, but they are not simple goods or services that can be purchased.

The typical retort from economists is that these outcomes still depend on goods and services. For example, educational services help us to find meaningful work, develop friendships and become the kind of person we want to be. Economists thus feel justified in measuring progress by the consumption of goods and services because these produce human wellbeing, even if only indirectly.

6 IVEN that the end goal is wellbeing, one might ask why we do not dispense with all the counting and valuation and just directly measure happiness. Happiness surveys essentially ask people to report their happiness by selecting one of a few ordered categories such as 'very happy' or 'somewhat happy'. 


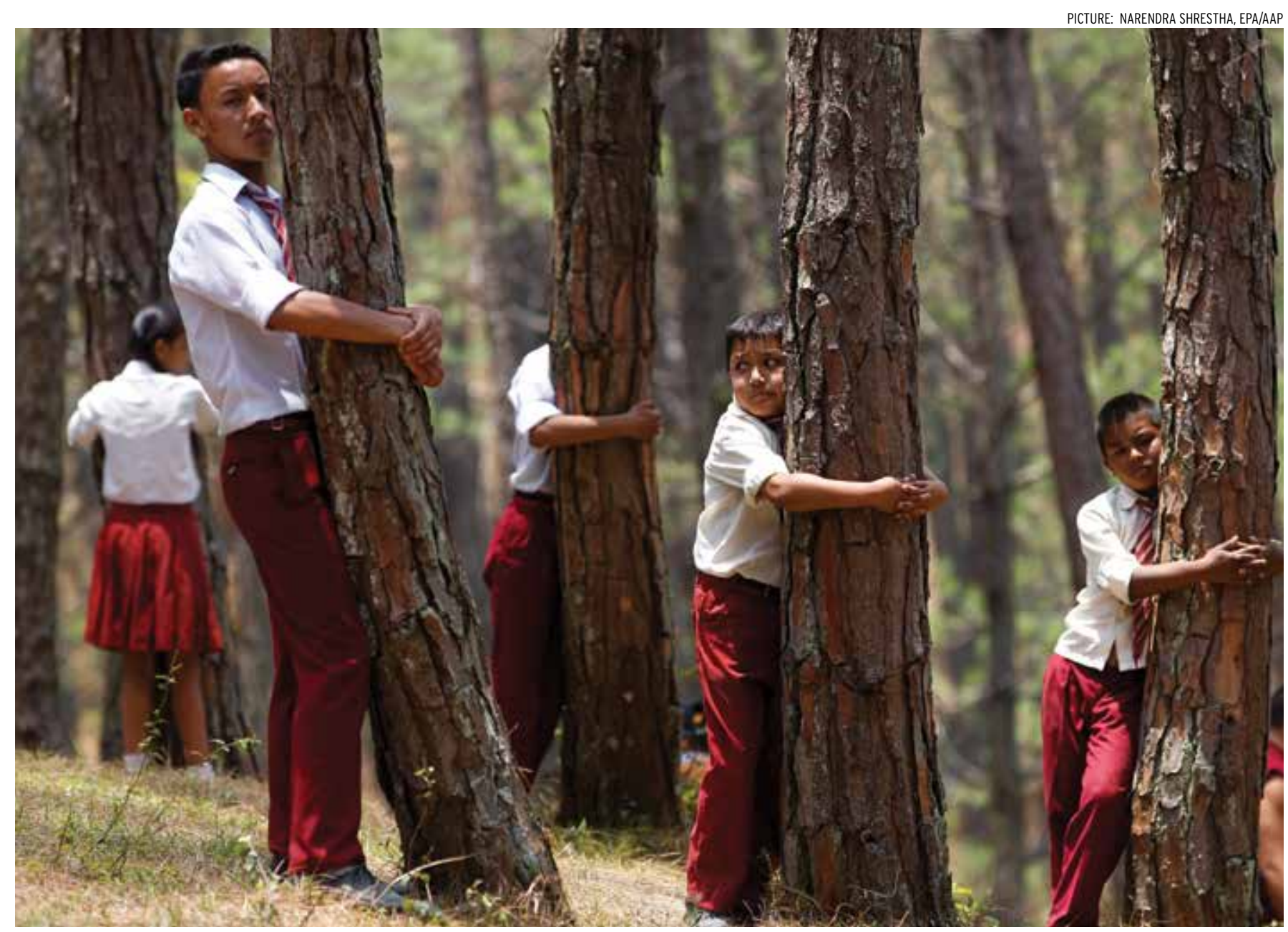

Nepalese pupils hug trees to celebrate World Environment Day at the forest of Gokarna near the capital Kathmandu. Natural capital like forests and fisheries and human capital in the form of skills and creative faculties are key elements of the productive base of an economy.

One can assign numerical values to these categories and then report how the average level of happiness in a country changes over time or in response to a certain policy.

But it is not possible to rank the overall happiness of two groups from a survey of this type without imposing some dubious assumptions. This makes happiness surveys of limited value in measuring development and progress.

ITHOUT some revolutionary advance in how we directly measure wellbeing, we are resigned to inferring it from measures of the quantity and social value of each good and service.
One issue on which we can make progress is measuring the potential for economic growth, the physical

This focus on goods and services when trying to measure development may seem restrictive. What about family, friendships, safety, meaningful work, recreation and other factors that determine human happiness? and human forms of capital that produce goods and services. Growth in a measure of consumption like GDP means that people are better off, but it does not mean that people will continue to enjoy the higher standard of living in the future. Sustainability means that comprehensive consumption can be at least as high in the future as it is now. An increase in the productive base today implies an increase in potential intergenerational wellbeing.

We could attempt to directly forecast intergenerational wellbeing without measuring wealth, but we can't know what future consumption will be. The term is thus more of a 
conceptual object than something that we have any hope of directly measuring. It is not surprising then that governments, development agencies and most economists focus on income growth along an optimal growth path when discussing sustainability.

$\mathbf{T}$ HIS is a mistake. We do not need to assume optimal income growth to assess sustainability. Sustainable development is not the same thing as optimal growth. Sustainable development simply requires that intergenerational wellbeing not be declining. Critically, high growth rates as traditionally measured may actually be harmful to intergenerational wellbeing where such growth undermines the productive base.

We may not be able to directly measure intergenerational wellbeing, but we can measure the productive base that is used to produce the goods and services that determine current wellbeing. The productive base includes all built, natural, human and social capital. A comprehensive measure of the productive base is preferable to a narrow measure as there are many goods and services that are not counted in GDP but still provide wellbeing, such as ecological services like air purification provided by forests and other natural capital.

Intergenerational wellbeing increases if and only if the productive base increases. Just as consumption is defined comprehensively to include all non-market goods and services that provide wellbeing, the productive base must be equally comprehensive and include all forms of capital that provide these goods and services. Measuring all these forms of capital and their social values would allow them to be aggregated into a single measure of wealth, referred to as inclusive or comprehensive wealth.

At present, there is too much emphasis on GDP and other measures of national income and not enough emphasis on national wealth. There have been adjustments to GDP-like green GDP or the human development index, which combines a set of social indicators and GDP with arbitrarily chosen weights. But these are still primarily measures of the current flow of wellbeing rather than measures of the stock of capital assets that make up the productive base. Without measuring how the comprehensive wealth of a country changes over time, we cannot evaluate if economic development is sustainable.

In particular, GDP growth does not necessarily indicate growth in wealth. For example, recent GDP growth in Cambodia has at times been accompanied by declines in inclusive wealth-a pattern seen in many countries in the region at various times over the past 25 years including Australia, India, Indonesia, Malaysia, New Zealand, and Papua New Guinea. This has obvious implications for sustainable development policy, as growth is of little value if its fruits are fleeting.

Those countries with a decline of inclusive wealth per capita are typically extracting more from the

We do not need to

assume optimal income growth to assess sustainability. Sustainable development is not the same thing as optimal growth. environment than they are investing in other forms of capital-like education (human) and infrastructure (built).

Wealth accounting is also useful for analysing the transformation of assets in the productive base over time. In particular, most Asian countries have recently seen large decreases in natural capital offset to some degree by large increases in built and human capital. An exception is South Korea, where natural capital is actually increasing, driven by renewable natural resources including forests.

D ATHER than replacing GDP, 1 a measure of national wealth would serve as a complement. Flow variables, like GDP, are more related to current wellbeing. Stock variables, like inclusive wealth, are instead related to potential intergenerational wellbeing. An increase in inclusive wealth implies that future citizens will inherit a larger productive base and will therefore be able to enjoy higher levels of wellbeing. Regularly produced national wealth statistics would reduce the obsession with GDP and would place greater focus on the importance of environmental and educational investment and longterm sustainability. EAFO

Kevin J. Mumford is an associate professor of Economics at Purdue University.

EASTASIAFORUM

IN OUR NEXT ISSUE ... CAN ASIA BREAK FREE? 


\section{A critical balancing act}

\section{R. QUENTIN GRAFTON, JOHN}

WILLIAMS AND QIANG JIANG

A SIA'S food systems are under an unprecedented confluence of pressures, including climate change. Balancing future food demand and supply in ways that protect the most vulnerable while also being sustainable in terms of energy, water and biodiversity must be a first order policy priority.

Demand for food is driven by population growth, income growth and urbanisation. Global population size is projected to increase from over 7.3 billion today to more than 9.5 billion by 2050 under a medium growth scenario.

Per capita income growth at 3 per cent a year will more than double average world income by 2050. More people and higher average incomes will result in greater food consumption and changes in diets. For instance, rapid growth in per-capita income over the past two decades in China has been accompanied by sharp growth in the consumption of livestock products. Intensive livestock production is much less efficient than direct crop consumption in providing food calories. Thus, as meat becomes a greater share of the calories consumed, proportionally more crops will need to be grown for the same amount of calories consumed.

D ECENT studies estimate food demand will need to increase by at least 60 per cent between 2005 and
2050. Notwithstanding the fact there are today about 800 million people in the world chronically undernourished, global studies show that it is necessary to increase global crop yield by a minimum of 1.1 per cent per annum to feed the world by 2050 . The current growth of average global crop yields varies between 0.9 and 1.6 per cent per year. The future challenge is whether crop yield increases on the lower end of this range, together with modest increases in cultivated land, will be sufficient to meet increased food demands.

Prospects for the future are all the more uncertain because past production has sometimes degraded or destroyed ecosystems, and depleted the natural resource base

PICTURE: ANUPAM NATH / AP PHOTO

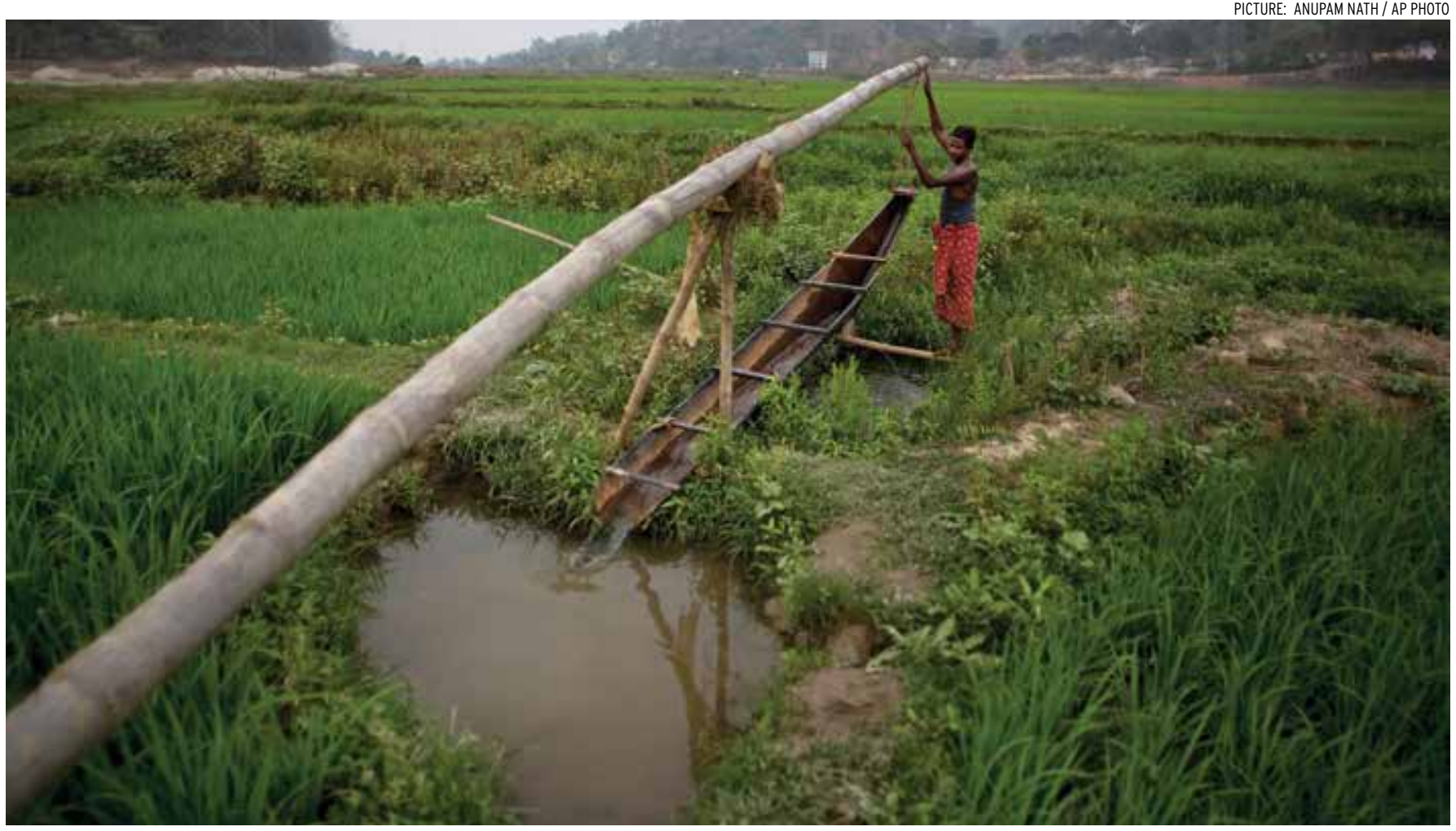

35 year old Indian farmer Niren Das manually irrigates his paddy field on the outskirts of Gauhati, India. About 60 per cent of India's population works in the agriculture sector. 
on which agriculture is ultimately dependent. The availability of suitable lands for agriculture is likely to be plentiful in only a few regions by 2050 . It is by no means clear whether additional increases in food supply are possible without further damage to local, regional and global ecosystems. Further, there is increasing competition for land, water and energy for uses other than for food production.

$\mathbf{s}$ UBSTANTIAL water deficits from agricultural water use alone are also likely to occur in key foodproducing countries, such as China and India. Increasingly high rates of crop water use will put very large demands on water resources. This could push global water use, even without other increases in industrial or household use, beyond the estimated safe operating boundary for the planet without changes in how extracted water is used in agriculture. The projected water deficit from cropping under current practices can only be eliminated by reducing water demand in other sectors, or by reducing water levels in surface flows or groundwater.

Climate change poses further risks to future food supplies. This is not just because of higher temperatures that are moderately negative for some plants and positive for some others. The major difficulty in terms of food supply lies in climate variability through a possible increase in the number of extreme weather events. Extreme weather events pose many challenges; not least that they make food prices more variable especially when there is inadequate food storages or restrictions on food exports in times of shortages.

Given bio-physical constraints such as the availability of land and water, technological improvements and efficiency gains are required. This is especially critical in tropical locations with low soil nutrient availability and water retention. In sum, there is a need for investment in research and development to ensure current rates of yield growth do not fall any further and that this is achieved without compromising the soils and water on which future food production depends. Equally as important, gaps between actual and potential yields must be overcome.

Food trade will be important for ensuring an adequate distribution of food across countries. Growing food shortages are predicted for South Asian countries such as India and Pakistan. These countries represent 'choke points' that are likely to remain even if global crop yields are sufficient in total. While there is genuine concern about how Asia will meet anticipated increases in food demand, globally agriculture has successfully responded to increased food demand over the past decades. Food supply has more than tripled since 1960 and continues to rise at a global level. Maintaining future supply growth, but in ways that ensure sustainable food systems is critical to successfully meeting the global food challenge.

ERTILISERS will play an increasingly important role in overcoming yield gaps, but complementary approaches are needed to promote sustainable growth in agricultural production. Provided sufficient nutrients are present, crop improvements through genetic modification and improved agricultural management can help overcome possible future food availability deficits. Adequate nutrients are crucial to ensuring the genetic capacity of the crop is fully exploited and even substantial improvements in potential crop yields and water productivity cannot offset critically- limiting nutrients.

Fertiliser can impose negative environmental costs on landscapes, as well as planetary nitrogen and phosphorus cycles. Reductions in its excessive use must be accompanied by methods of crop production that offset the expected decline in yields. For countries such as China and the United States, which are highly dependent on crop fertilisation, finding ways to deliver nutrients essential to food production that do not have negative impacts on soils and landscapes and without further contributing to greenhouse gas emissions is a major challenge.

7 HE sustainability of the food production system is being questioned in a world with intensive agriculture. Current agricultural production and distribution already leaves hundreds of millions of people hungry in the world while growth in agricultural production under a business-as-usual model will likely contribute to the planet approaching or even surpassing its safe operating space in terms of biodiversity, climate change and the nitrogen cycle. Land, biodiversity and water degradation have, and will continue, to restrict growth in food availability in the coming decades. Effectively responding to the nexus of food security and environmental risks will be a key policy challenge for Asian countries in the coming decades. EAFQ

Quentin Grafton is a professor of economics at the Crawford School of Public Policy, ANU and Editorin-Chief of Policy Forum.net. John Williams is an adjunct professor at the Crawford School of Public Policy, ANU and adjunct professor at CSU Institute of Land Water and Society.

Qiang Jiang is an associate research fellow at Sichuan University, China. 


\section{ST CENTURY INDUSTRIALISATION}

\section{Productivity lessons for Asia's tiger cubs}

\section{LAWRENCE J. LAU AND JUNGSOO PARK}

T HE high and persistent growth of the four Newly Industrialised Economies-also known as the East Asian Tigers: Hong Kong, South Korea, Singapore and Taiwan-from 1970 to 1990 prompted much debate about the drivers of growth in these economies. There have been numerous studies looking into this issue, but they have not yet been able to reach a common conclusion. Understanding the drivers of growth in the Tiger economies can help us grasp the future prospects for growth in the emerging Asian economies, and for Asia more generally-and the supporting policy responses needed.

Some studies examining growth in these economies suggest an assimilationist view, claiming that a high rate of technological changefrom technology infusion-was the main driver of growth. They argue that globalisation helped these economies to adopt advanced foreign technologies at low cost and develop new skills based on the absorbed technologies. They attribute much of the success of the Tiger economies to government interventions that facilitated assimilation into the global economy and policies that promoted growth in exports. The growth pattern consistent with this notion is denoted as 'productivity-based growth'.

o THER studies suggest an accumulationist view. Here the main source of growth was from the rapid accumulation of capital. These studies calculate total factor productivity (TFP) estimates, or estimates of technical progress, and typically find measured TFP growth to be relatively small. The growth pattern PICTURE: DALE DE LA REY / AFP PHOTO

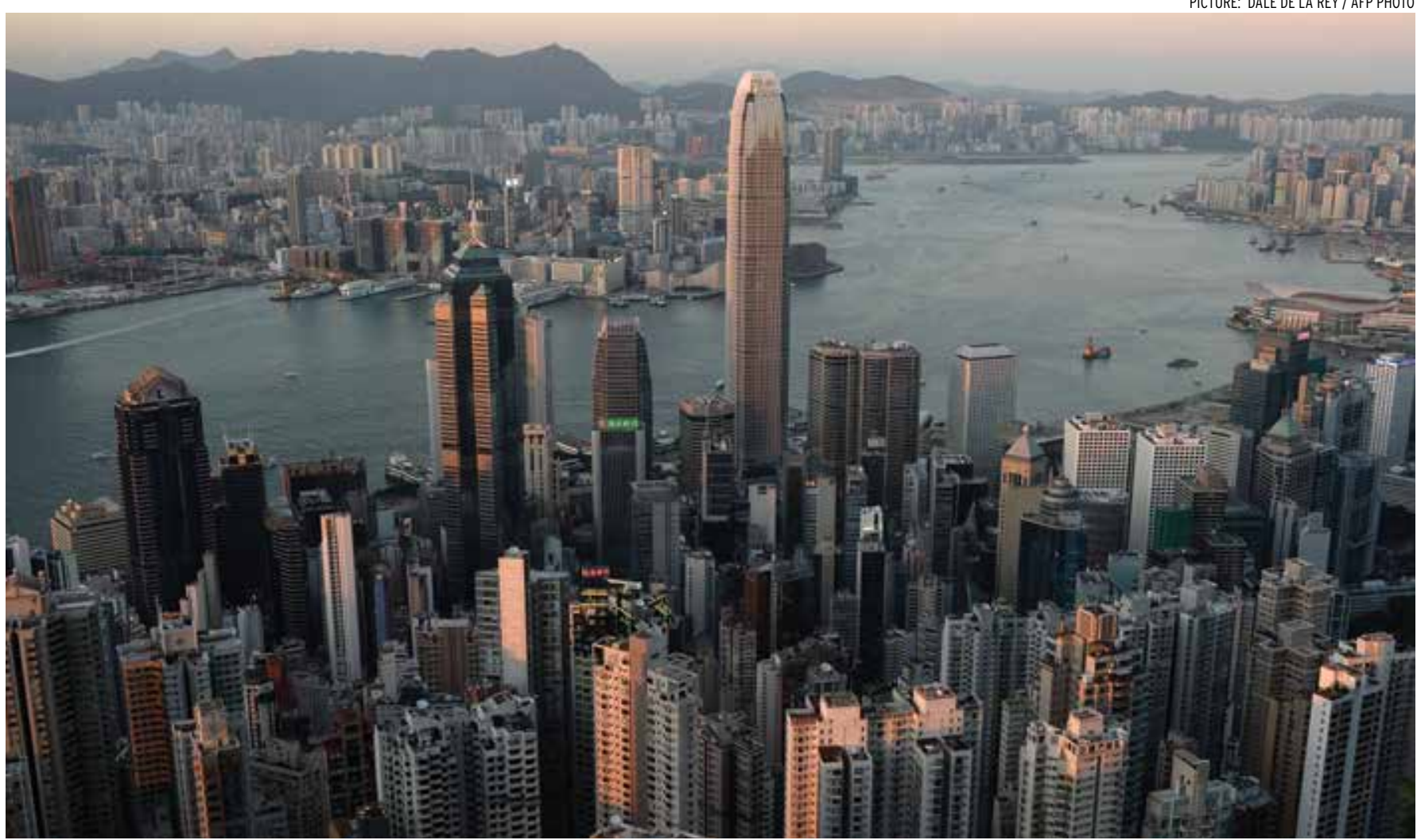

Victoria Harbour in Hong Kong is famous for its fast flowing commerce. Trade and openness helped the small island nation and other Asian 'Tigers' to develop rapidly by assimilating foreign technology. 
consistent with this notion is denoted as 'input-based growth'.

More than 20 years after this period of rapid growth in the East Asian Tigers, a new group of Asian economies-Indonesia, Malaysia, the Philippines and Thailand from ASEAN, as well as China and Indiahave emerged with similarly high and persistent growth starting from the 1990s. At the same time, growth has slowed in the original Tigers. There is now more evidence on the nature and origin of growth in Asia's industrialising and industrialised economies, allowing new insights into the future of productivity in the region.

C OMPARING the patterns of productivity growth over the past few decades of the Asian economies with those of the advanced economies, it is evident that the Asian economies are in a process of transition between these two growth paradigms. Specifically, decomposing growth rates and determining the driving factors of TFP growth reveal that the four Tigers have already made the transition from input-based growth, supported by the accumulationist view, to productivity-based growth, supported by the assimilationist view. This is consistent with the growth patterns seen in advanced economies in the earlier phases of their economic development.

Among the other Asian economies, signs have begun to emerge over the last decade of their own transition to productivity-based growth. Similar to the experience of the first four Tigers from 1970 to 1990, these economies may face fiscal challenges that may slow their growth in the post-transition period. Their need to transition fully to productivity-based growth recommends future public policies based on the experience of the Tiger economies and the challenges currently facing advanced economies outside of Asia.

Examining trends in the variables affecting TFP growth allows assessment of the potential for future productivity growth. One of the main factors in increasing productivity growth is human capital. The rising educational attainment rates seen in the four ASEAN economies and China is expected to have a significant impact on productivity. But their levels of educational attainment are still far below the average level of the Group of Five (G5) countries (France, Germany, Japan, the United Kingdom, and the United States), and significant challenges remain for public policy in this area across the region.

Another factor in increasing productivity growth is investment in research and development (R\&D). R\&D-to-GDP ratios for the G5 have fluctuated since the 1970s but have shown a slight upward trend in recent years. Although South Korea, Singapore and Taiwan started with very low levels of R\&D-to-GDP ratios, they have significantly increased their resources devoted to $R \& D$ since the 1980s. The four ASEAN countries tend to have low R\&D-to-GDP ratios, with little indication of any increase at this stage. But while the Chinese R\&D-to-GDP ratio has seen strong upward movement and has now caught up with the United Kingdom, it still lags significantly behind those of not only the advanced economies of Germany, Japan and the United States, but also South Korea and Taiwan.

NVESTMENT in R\&D leads to innovation outputs that can be measured in a number of ways, including the number of patents granted. Focusing on patents granted by the United States Patent and
Trademark Office, the number of patents granted to the four emerging ASEAN economies are still quite low, even though they have begun to rise significantly since the late 1990s. The same goes for China, which has again caught up with the United Kingdom. Yet on a per capita basis, the number of US patents granted to Chinese nationals is still very low. Trade and foreign direct investment are additional channels of technology transfer. Global trade and capital flows have intensified especially in these Asian regions. The stock of inward foreign direct investment has increased 7.6 times in the Tiger economies, 6.1 times in the emerging ASEAN economies, 13.9 times in India and 2.9 times in China since 2000.

7 HE Asian economies are in the process of transitioning their pattern of growth. Asia's Tigers seem to have already transitioned from input-based to productivitybased growth, and the other Asian economies appear to be following this path. This reality should guide public policy in tackling the fiscal challenges that lie ahead. Investment in intangible capital such as human capital and $R \& D$ have been and will continue to be the main determinants of TFP growth in Asia. Recent trends in human capital, R\&D, and trade and capital flows in the Asian region all suggest that productivity growth is likely to be stronger in the region than before and can be expected to drive its economic growth in coming decades.

Lawrence J. Lau is the Ralph and Claire Landau Professor of Economics at the Institute of Global Economics and Finance, The Chinese University of Hong Kong. Jungsoo Park is professor of economics at the School of Economics, Sogang University, Seoul. 


\section{AUSTRALIA}

\section{Keeping productive after the boom}

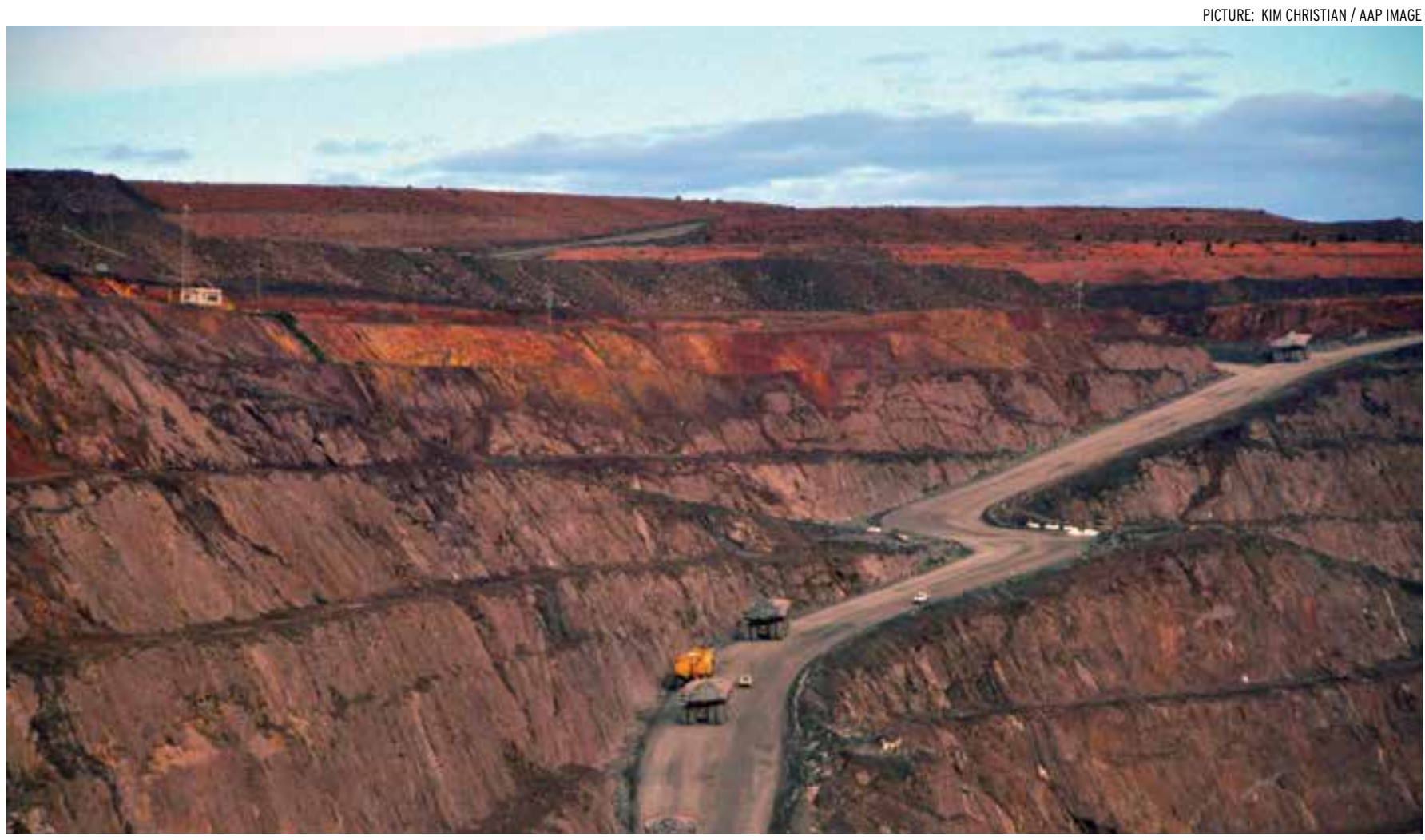

Kalgoorlie Consolidated Gold Mines (KCGM) Superpit gold mine operations on the outskirts of Kalgoorlie in South-West Australia. The Superpit is one of the world's largest open pit gold mines.

\section{JENNY GORDON}

$\mathbf{T}$ HE 2015 Intergenerational Report assumed that labour productivity would grow at an average annual rate of 1.5 per cent over the period 2015 to 2055 . This is slightly lower than the growth in labour productivity over the last decade, but that came entirely from capital deepening (growth in capital services rising faster than labour inputs). This is because multifactor productivity (the amount of output that Australia has been producing per unit input, as best it can be measured) has stagnated. With the boost in income growth from the terms of trade coming to an end, labour productivity growth will be the primary driver of future income growth. And as capital investment growth is likely to slow with the end of the mining boom, restoring multifactor productivity growth will be critical to delivering on even this more modest labour productivity growth projection.

Australia's strong productivity performance over the 1990s has been attributed to considerable microeconomic reform, investment following the liberalisation of trade and capital markets in the 1980s, and increases in human capital as more Australians opted to undertake higher secondary and tertiary study. A subsequent easing of Australia's productivity growth since the 1990 s was to be expected, but the ongoing deterioration is a concern.

OME of the sources of the recent $\checkmark$ poor productivity performance are temporary. This includes the effect on agriculture and water service utilities of drought in 2002-03 and 2006-07 to 2009-10. It also includes the lag in capital investments coming online in mining and some 
utilities. While capital is counted in productivity statistics at the point of investment, large capital projects can take some time to be fully utilised. So where investment in large projects is accelerating, as in the mining boom up until 2012, utilisation will increasingly lag investment, appearing as poor productivity growth (an increase in inputs without an matching increase in output). But given the price falls in some mining industries, apparent overinvestment in mining dampens the expected recovery in productivity growth as not all the capital is likely to be fully utilised in the near future.

OME of the sources of recent $\checkmark$ poor productivity growth are more systemic. As mining resources are depleted and environmental services, such as surface water, come under increasing pressure productivity is negatively affected. More purchased inputs are needed to maintain production, whether it is removing more overburden to access the minerals, or having to invest in manufactured water to meet demand in low rainfall periods or in response to population growth. Such higher costs of production come as the 'free' environmental inputs decline, due to depletion or a community desire to protect what is left.

Another source of poor productivity growth is more speculative. It appears that consumers are managing to capture productivity improvements provided by higher quality products. While national statistical agencies do quality adjust some prices, this is difficult with completely new products with new functionality. Some new technologies, such as Google search and Twitter, have considerable value for consumers, yet are available free. When used by producers, these technologies should lower the firm's cost base and the value add should be reflected in higher productivity until competition forces prices down and consumers once again win. With models for how to monetise such technologies still developing, nominal GDP growth will lag behind the growth in value to consumers. The trend to consumers capturing a greater share of real value added may be growing, which would imply lower GDP growth relative to the real underlying growth in productivity.

So what are the prospects for productivity growth? Disruptive technologies that are improving connectivity, creating new resources, and transforming production processes as well as new products, offer exciting but uncertain prospects. Digital platform technologies, such as UberX and Airbnb, enable greater utilisation of a range of assets, including household cars and homes. Data are a growing resource that can be mined for new value-adding services, and the knowledge generated could transform how things are produced. Better informed consumers may be able to demand better goods and services, forcing productivity improvements in firms. Just how disruptive technologies will impact on nominal GDP is uncertain, partly because of the potential for consumers

Effort on many fronts will

be required to improve

Australia's productivity,

not least in human

services and public

infrastructure investment. to capture much of the benefits, and as these technologies increase the potential for more activity to take place outside the formal economy.

D ISRUPTIVE technologies aside, Australia faces some long-term challenges to productivity. The good news is that even if it does not fully appear in productivity statistics, the benefits of higher quality products can compensate consumers for slower wage growth. For governments, there is also good news in that capital utilisation rates should rise, if slowly, in mining and some utility sectors.

There is also less welcome news. The depletion effect on land, mining, water and other natural resources will continue to increase the real cost of production for-and thus the productivity of-many industries that rely on these inputs. Like climate variability and periodic droughts, climate change will affect agricultural and utility productivity over time. Regulation to protect the environment comes with a productivity cost, while failure to protect the environment by switching to renewable resources can impose costs to future productivity through the deterioration in the quality of natural resource inputs.

D REFERENCES for nonmarket outcomes-whether environmental or social-could see a shift in Australia's output mix toward production that sacrifices some market efficiency for more of the non-market product. Like quality for consumers, this trade-off is welfare enhancing, but it does not necessarily add to nominal GDP or measured productivity.

But there are opportunities. The most obvious is to better utilise investments in education and skills by raising labour force participation rates and hours worked, particularly for mothers and older workers, but also for youth. The government can 
also make and encourage wise public and private investments in education, infrastructure, and research and development. Here, technology and open data should enable innovation.

However, investment alone does not deliver productivity growth and governments can invest too much. Investment in infrastructure tends to go to major projects, often with uncertain utilisation, long build times and associated capital lags. Take for instance Australia's major investment in electricity poles and wires in the early 2000s. This was mainly done to secure supply. But the importance of security was not put to consumer market testing and, partly because peak demand only occurs a few days a year, low rates of utilisation of this investment has left productivity well below potential. In such scenarios, competition when prioritising investments should be based on cost-benefit assessments, aligning incentives and risk with the capacity to control and regulate.

\section{USTAINABLE government \\ $\checkmark$ revenue is key to sustainable} funding of government services. Yet growth in nominal GDP, on which the tax base depends, may settle at below previous historical rates for the reasons discussed above. In addition, to the extent that the tax revenue base relies more on wage income and consumption, the trend over the last decade of a falling labour share of income will also affect revenue. Governments are likely to face a choice of changing how they raise tax revenue or substantially lowering their funding for services.

This makes it even more imperative to improve productivity in the delivery of human servicesparticularly education, health and social services-which are a growing share of the Australian economy. Technology will play a role, but productivity has to be driven by incentives to adopt, adapt and invest in developing new technology, reorganise production or develop new, better targeted services.

Empowering consumers to drive welfare-enhancing market solutions through client-directed subsidies, which gives consumers choice over providers and to some extent services so that firms have to compete for clients, can play a role. But such mechanisms can have unintended consequences and affect equity. And there are areas of human services where markets will not provide solutions, so caution is needed. Here, different ways are needed to drive productivity growth, and more work is required to better understand how to boost productivity.

C FFORT on many fronts will be required to improve Australia's productivity, not least in human services and public infrastructure investment. Progress requires the support of the public and acceptance that trade-offs have to be made to better align incentives for productivity improvements with the decisions that people, firms and government have to make about their consumption, labour supply, and investment now and for the future. EAFO

Jenny Gordon is principal adviser (research) at the Australian Productivity Commission. The views expressed in this article are those of the author and do not necessarily reflect those of the Productivity Commission.

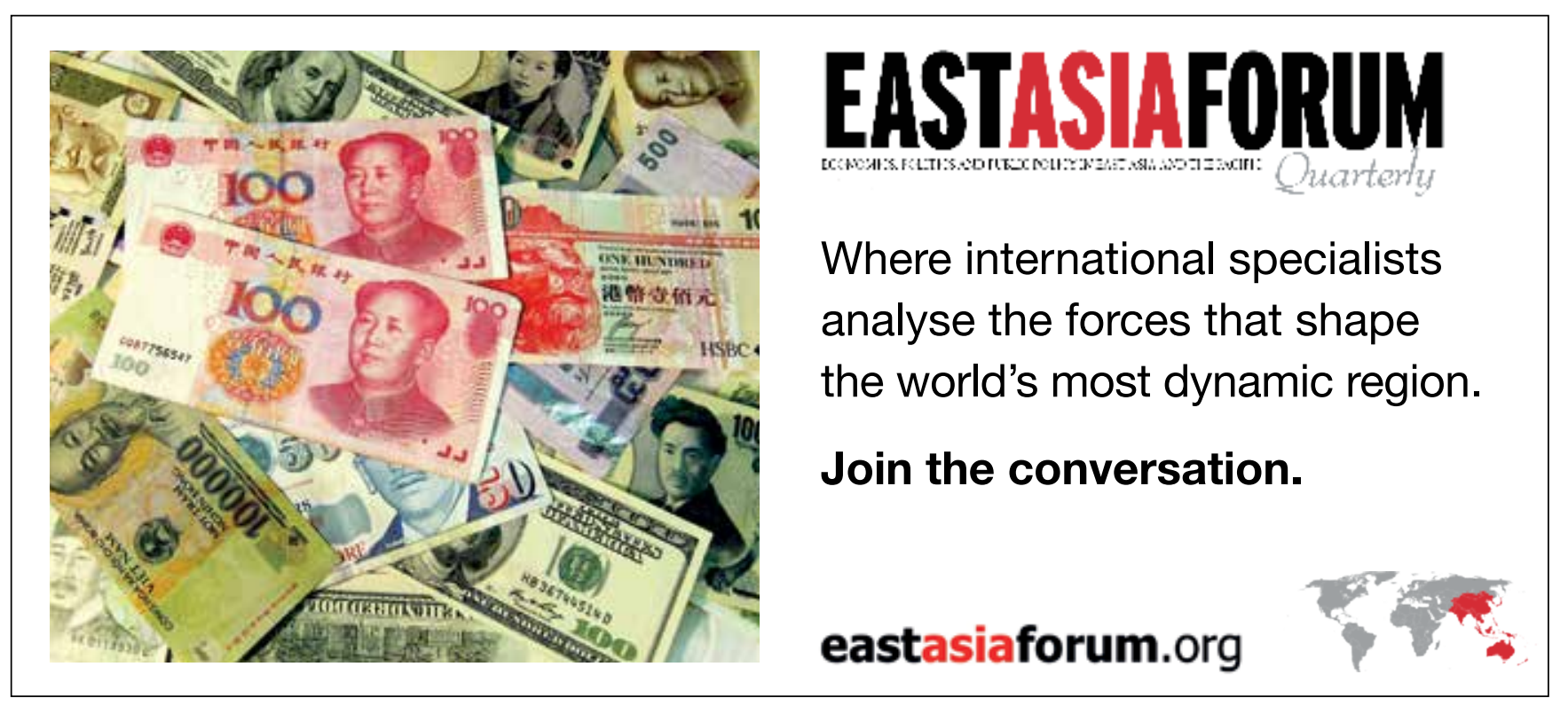



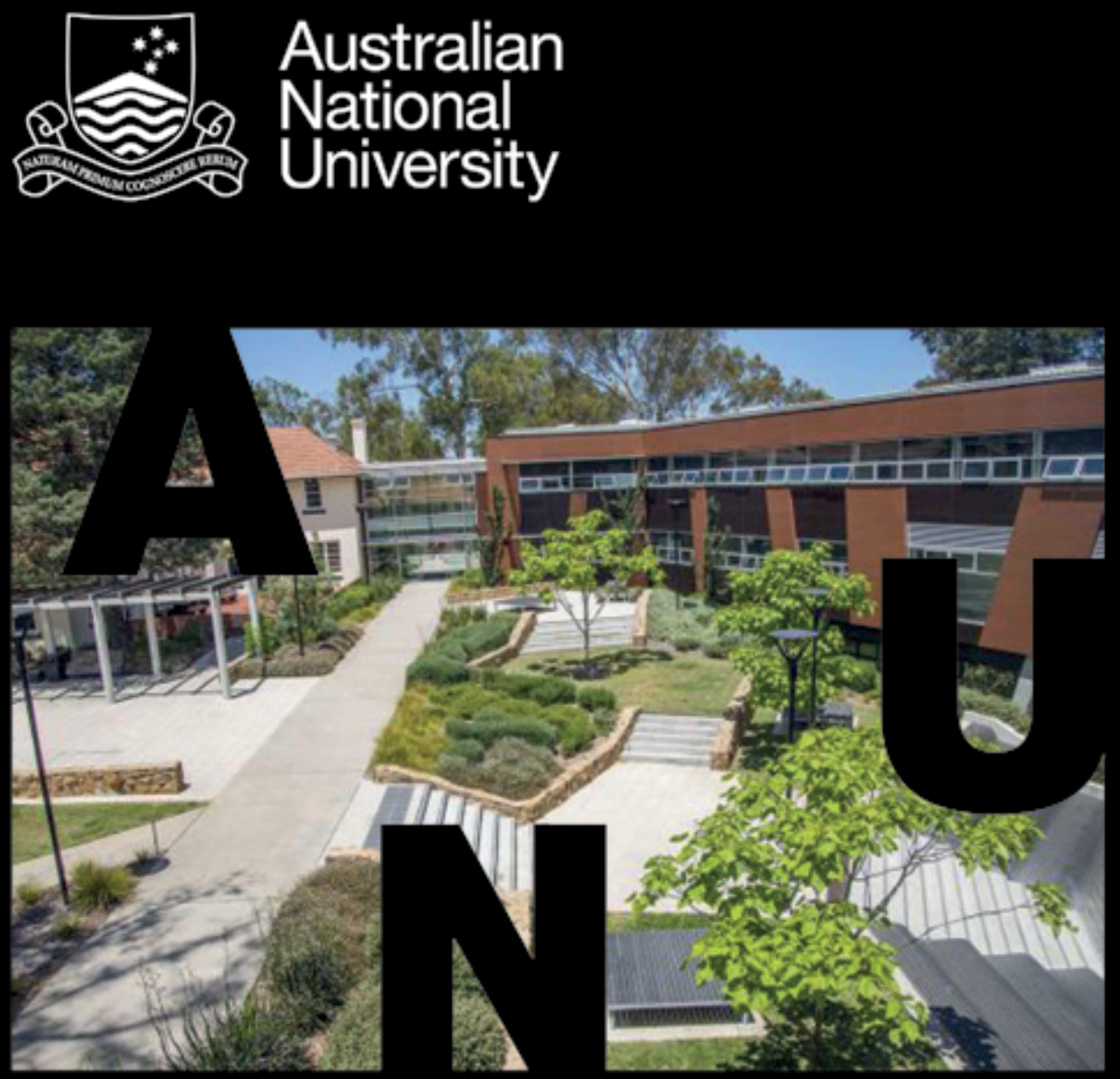

\section{PUBLIC POLICY AT \\ AUSTRALIA'S TOP RANKING UNIVERSITY*}

ANU Crawford School of Public Policy is renowned for world-class research, education and policy engagement, leading and shaping policy thinking in Australia, Asia and the Pacific.
Crawford School staff and visitors are active on government committees and work in advisory roles across government, business and civil society.

Join our vibrant policy community, which brings together scholars, students, policy-leaders and policy practitioners from the public, private and NGO sectors in Australia, the region and globally.
Explore your options for research partnership, postgraduate study and executive education in the following: $>$ Public policy

$>$ Public administration

$>$ Applied economics

$>$ International development

$>$ Environmental and resources management, and $>$ National security. 